\title{
The Four Steps to the Fifth State of Matter
}

\author{
Dr.(Prof.) V.C.A. NAIR* \\ Educational Physicist and Research Guide for Physics at JJT University, Rajasthan-333001, India. \\ *nairvca39@gmail.com
}

\begin{abstract}
Instead of keeping the title of the paper as simple as "The Fifth State of Matter" or "The Bose-Einstein Condensate", the author has purposely chosen the present title in order to create interest amongst the readers. Starting right from Robert Boyle of the seventeenth century and right to the end of the twentieth century, the contents of the paper is divided into four steps as per the title of the paper, each step corresponding to a century. Thus the reader might expect some change in the research methodology. For a reader, generally, thinking comes during reading or after some reading. The author advises the readers to go through the entire paper at a stretch and understand the history and philosophy of the subject. As a picture speaks thousand words, pictures of scientists are given at appropriate places. Some of the illustrative diagrams are drawn by the author himself. As research papers on a topic of this kind are very rare, the author has taken material from some classical books. Mathematics, being the language of Physics appears at some places and hence the paper is meant for physicists and chemists.
\end{abstract}

Keywords: Absolute scale, Absolute zero, Adiabatic demagnetization, Bose condensation, Boyle's law, Charle's law, Gay Lusaac Law, Helium atom, Hobbe's freezing dispute, Joule-Kelvin effect, Laser cooling, Magneto Optical Trap, Nernst Heat Theorem, Pressure coefficient, Van der Waal's equation, Volume coefficient.

\section{INTRODUCTION}

This research paper is more of a historical nature. In any subject or topic for that matter, what is not known is the history and philosophy behind it. The history of Absolute Zero stretches right from Robert Boyle of the $17^{\text {th }}$ century right to the end of the $20^{\text {th }}$ century met with the miracle when in 1995 the trio Eric Cornel, Carl Wieman and Wolfgang Ketterle of the United States could successfully approach very near to Absolute Zero as near as nobody so far could reach with the lowest possible known temperatures. Maintaining the title of the paper in letter and spirit, I have divided the paper in four main headings as Step-1, Step-2, Step-3 and Step-4 as if the reader is climbing step by step and finally reaches absolute zero as shown in the illustration of Fig.1 in which each step corresponds to a century. One might feel my presentation is like an epic wherein it is of interest to see various characters and hence I have added ppictures of scientists at most of the places. In fact they are the stars or pillars of investigation and findings.

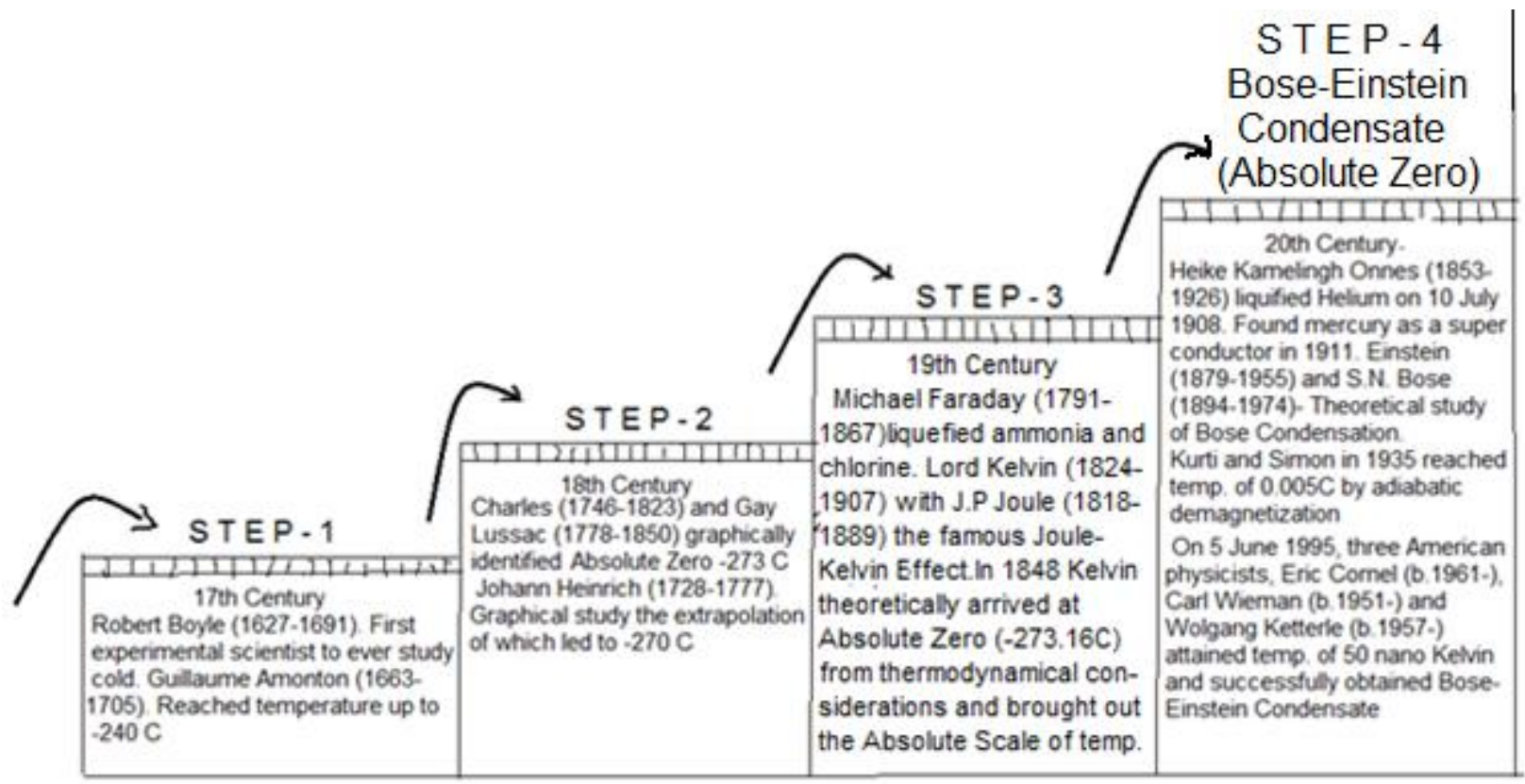

Fig.1 Illustration of various Historical Steps to attain Absolute Zero 


\section{IARJSET

\section{REVIEW OF LITERATURE}

\section{STEP - 1}

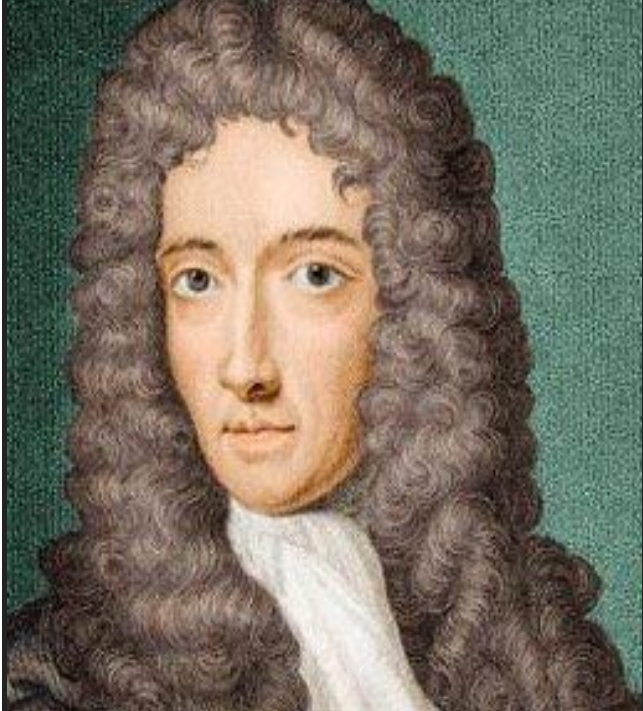

Fig.2 Robert William Boyle (1627-1691)

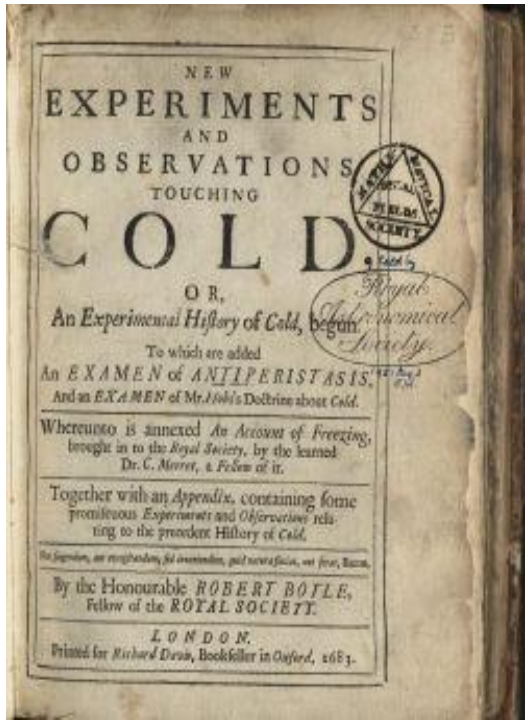

Fig.3 The title page from New Experiments and Observations Touching Cold by Robert Boyle

Robert Boyle (1627-1691) (Fig.2), the Anglo-Irish natural philosopher, chemist, physicist and inventor was the first scientist to ever study "Cold". Boyle's lesser known work is "New Experiments and Observations Touching Cold" the title page of which is shown in Fig.3. His work is preserved in the Burns Library, Boston College. In the year 1665 he pioneered the idea of a minimum low temperature, of course not of absolute zero, the concept of which was not even born in his times and he called this lowest temperature "Primum Frigidum" Some of the physical apparatus used by Boyle is shown in Fig.4.

Boyle studied the anomalous behavior of water at $4^{\circ} \mathrm{C}$. When water is cooled it contracts up to about $4^{\circ} \mathrm{C}$ and slightly expands till the freezing point and when it freezes it expands approximately $9 \%$. He also found that it takes 75 pounds of its weight to keep the cork from popping out when water froze (Fig.5).

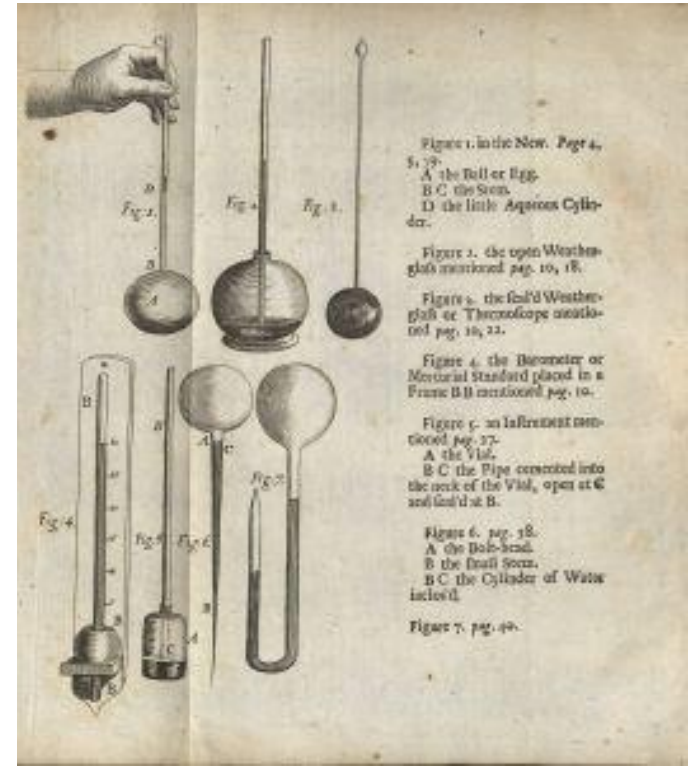

Fig.4 Some of the physical apparatus used by Robert Boyle in 1683

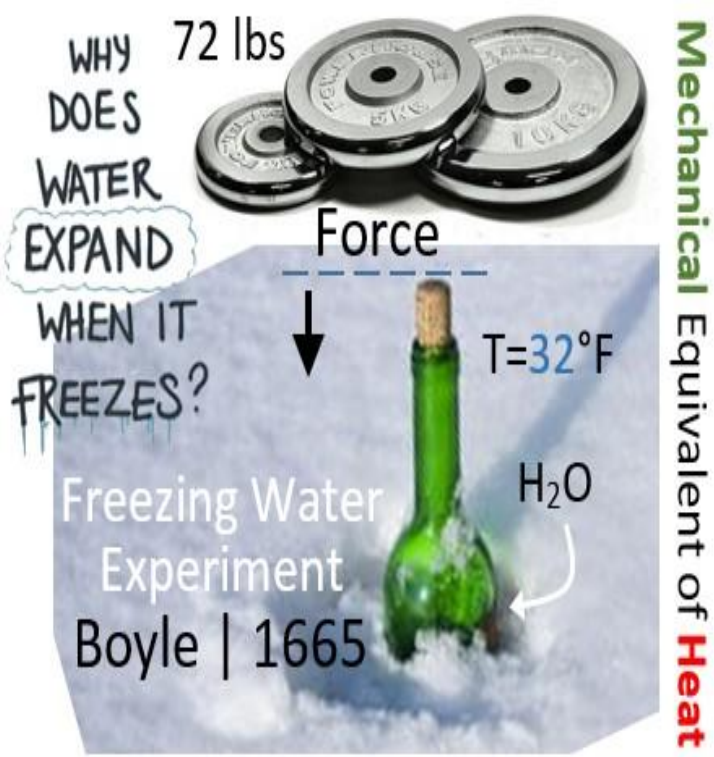

Fig.5 Illustration of the anomalous behavior of water by Robert Boyle in 1665 


\section{IARJSET \\ International Advanced Research Journal in Science, Engineering and Technology \\ ISO 3297:2007 Certified \\ Vol. 5, Issue 3, March 2018}

\section{Hobbe's freezing dispute:}

In circa 1660, Boyle engaged into a supposedly decade-long debate with Thomas Hobbes on the nature of freezing. The entry on "freezing" from the 1765 Complete Dictionary of the Arts and Sciences, reads as follows: (Q $)$ "FREEZING, in philosophy, the same with congelation. Philosophers are by no means agreed as to the cause of this phenomenon. The Cartesians account for it by the recess or going out of the ethereal matter from the pores of the water. The 'corpuscularians', on the other hand, attribute it to the ingress of frigorific particles, as they call them: Hobbes asserts, that these particles are nothing else but common air, which entangling itself with the particles of water, prevents their motion. Others will have a kind of nitrous salt to be the cause of congelation, by insinuating itself between the particles of water, and fixing them together, like nails: and indeed it seems probable that cold and freezing do arise from some substance of a saline nature, floating in the air; since all salts, and particularly nitrous ones, when mixed with ice and snow, greatly increase their cold and even bulk."

Hobbes' cold theory, to note, seems have some type of association to Pierre Gassendi's theory of hot and cold, which he acquired from Epicurus, according to which a body would be hot if it contained "calorific atoms" and cold if it contained "frigorific atoms". (Q $\underline{\text { ) }}$

Boyle also disproved Epicurus' theory of "cold corpuscles", which were said to work by stealing insensibly into liquors they insinuate themselves into, without any show of boisterousness or violence. Cold corpuscles were said to be "swarms of frigorific atoms". Boyle also disproved Thomas Hobbes' theory that the source of all cold was the wind by freezing live animals in a vacuum, an often misunderstood anecdote.

Boyle, in any event, to disprove Hobbes' cold theory, froze a bird in a vacuum, as shown in Fig..6

Such disputes arose because at the times of Boyle, people knowing something about the subject were few and people knowing nothing were many.

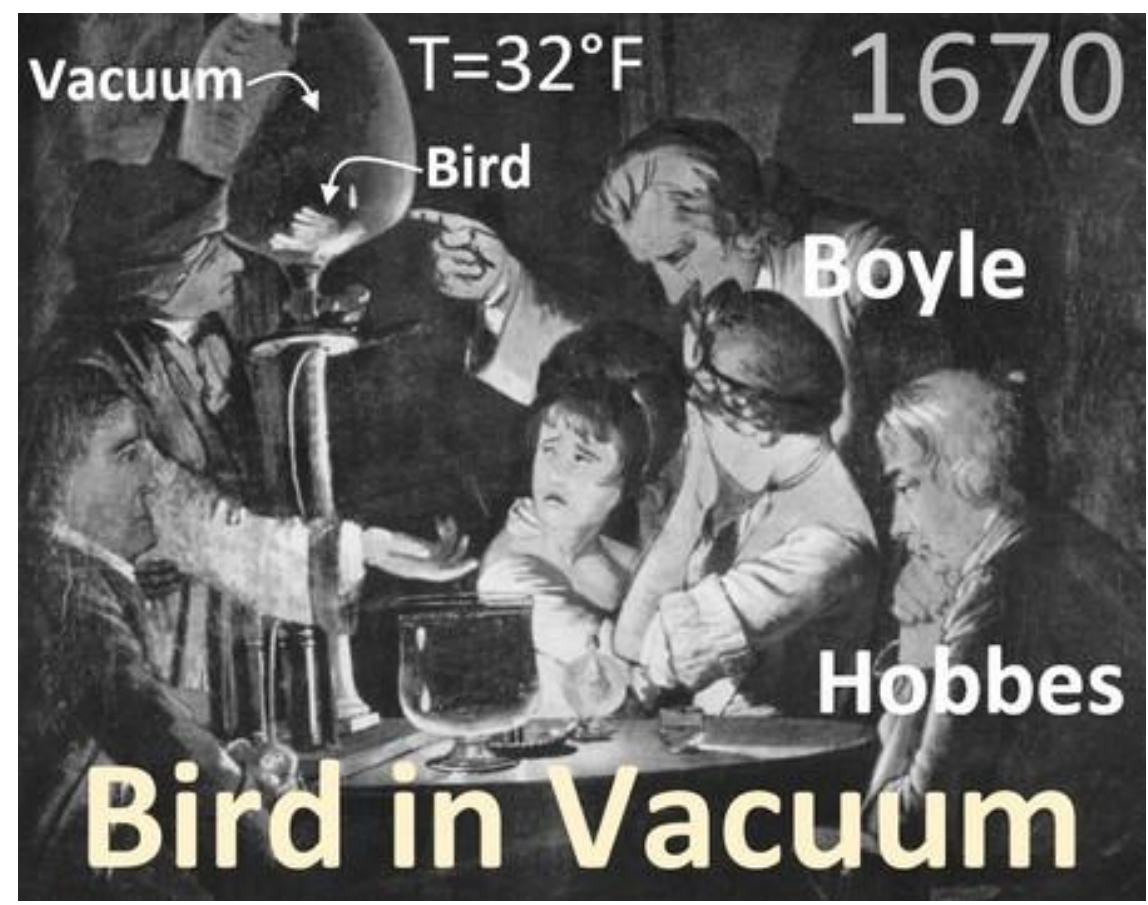

Fig.6 Boyle's demonstration of freezing a bird in vacuum

Boyle entered into the field of gases. He noticed that the three variables that affect any quantity of gas are temperature, $\mathrm{t}$, volume, $\mathrm{v}$ and pressure, $\mathrm{p}$. They are the three amigos of thermodynamics. Anything changes with temperature. In fact it plays a pivotal role in the field of thermodynamics and that is the reason why physicists rather thermodynamists gave it a prime importance by keeping its place before the first law, that is, the zeroth law of thermodynamics, according to which a number of bodies in thermal equilibrium in an enclosure, will have the same temperasture. We now come to our title of the paper. The step-1 starts with Robert Boyle of the $17^{\text {th }}$ century.

To start with Boyle took a certain quantity of air which is a mixture of gases kept the temperature constant and systematically varied the pressure $\mathrm{p}$ and noted the corresponding changes in the volume $\mathrm{v}$. A graph of reciprocal of volume versus pressure is shown Fig.7. 
Boyle published this result in 1662. With its publication he emulated his hero Galileo for the first time. Galileo firmly believed that the world could be explained using mathematics - as indeed Pythagoras had in a much earlier age. Boyle had now shown by experiment that air follows mathematical laws.

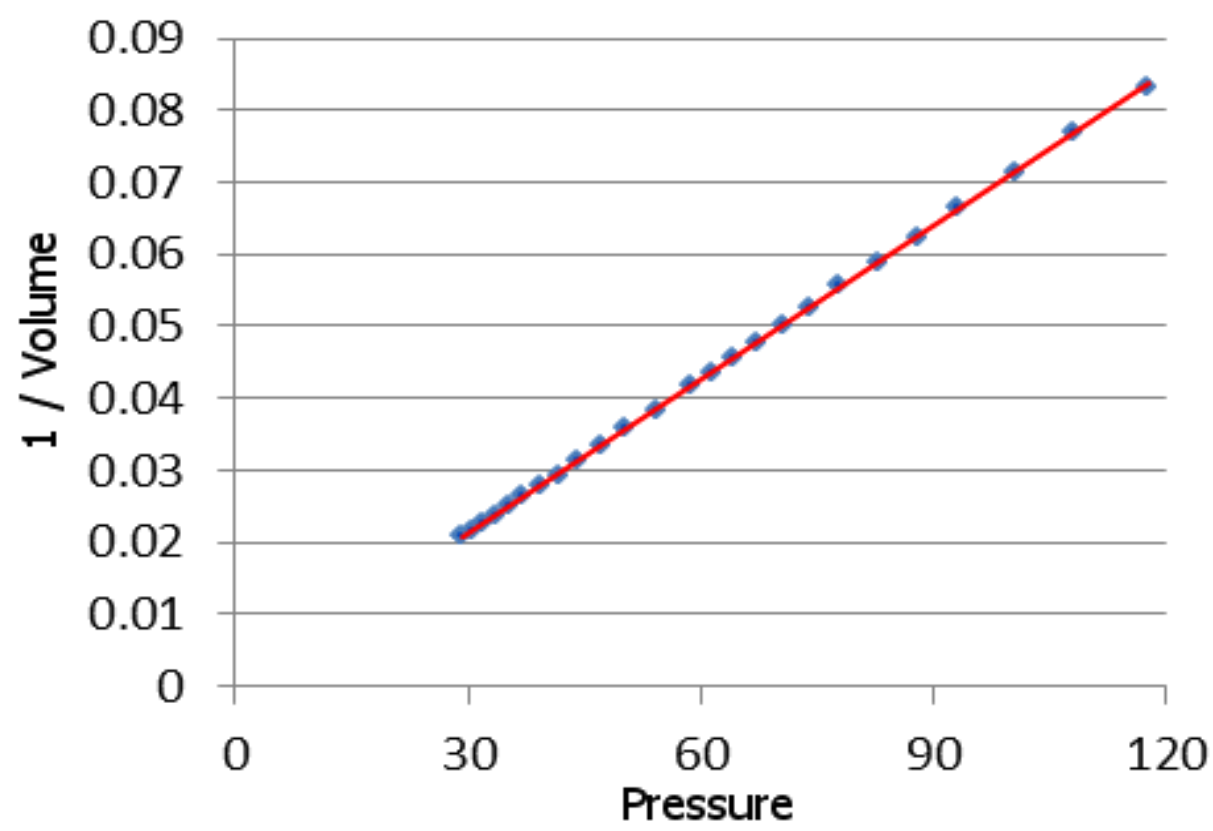

Fig 7. A graph of Boyle's actual experimental results. Reciprocal Volume is plotted vs. Pressure, producing a straight line. The data for the graph are taken from Boyle's work: A Defence of the Doctrine Touching the Spring And Weight of the Air.

\section{STEP - 2}

3.1 The Gas Laws: After the work of Boyle, experiments with gases continued in the $18^{\text {th }}$ and $19^{\text {th }}$ centuries. As mentioned in the elementary book, but really classical book by Lloyd W. Taylor [8], the first reliable experiments on expansion of gases were performed by the French inventor, mathematician, scientist and balloonist, Jacques Alexander Cesar Charles (1746-1823) (Fig.8) who is famous for the launching of the world's first unmanned hydrogen-filled balloon in 1783.In the year 1787 unlike Boyle who kept the temperature constant, he kept the pressure constant and varied the temperature of a certain quantity of gas and studied the changes in the volume. Thus, for any gas we may write [5]

$$
\lim _{p \rightarrow 0}\left(p v_{t}=\lim _{p \rightarrow 0}\left(p v_{)_{0}}(1+\alpha t)\right.\right.
$$

where $\alpha$ is a constant. In the limiting case the equation ( ) becomes

$$
(\mathrm{v})_{\mathrm{t}}=(\mathrm{v})_{0}(1+\alpha \mathrm{t})
$$

This is the equation of Charle's law. The constant $\alpha$ is the coefficient of expansion of the gas between temperatures $0^{\circ} \mathrm{C}$ and $\mathrm{t}^{\circ} \mathrm{C}(\mathrm{t}>0)$ and is found to be the same for all gases. The work of Charles was, however, not published.

Fifteen years later that is in 1802 just at the beginning of the $19^{\text {th }}$ century, the French physicist and chemist, Joseph Louis Gay Lussac (1778-1850) (Fig.9) performed the same experiments with better techniques and results. Unlike Charles, Gay lussac kept the volume constant and re-wrote equation (1) That is:

$$
\lim _{v \rightarrow 0}(p v)_{t}=\lim _{v \rightarrow 0}(p)_{)_{0}}(1+\beta t)
$$

where $\beta$ is a constant and equation becomes

$$
(\mathrm{p})_{\mathrm{t}}=(\mathrm{p})_{0}(1+\beta \mathrm{t})
$$

From equations (1a) and (2a) we can write

$$
\alpha=\frac{v_{t}-\mathrm{v}_{0}}{v_{0} \mathrm{t}} \text { and } \beta=\frac{\mathrm{p}_{t}-\mathrm{p}_{0}}{\mathrm{p}_{0} t}
$$




\section{International Advanced Research Journal in Science, Engineering and Technology}

ISO 3297:2007 Certified

Vol. 5, Issue 3, March 2018

$\alpha$ and $\beta$ are the volume and pressure coefficients respectively of the gas and Gay lussac found the value of $\beta$ same as that of $\alpha$ of Charles. He concluded:

"That all gases, speaking generally, expand to the same extent through equal ranges of heat; provided all are subject to the same conditions."

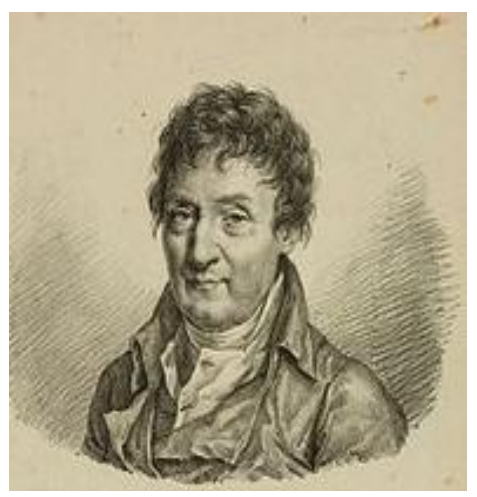

Fig.8 Jacques Alexandre Cesar Charles (1746-1823)

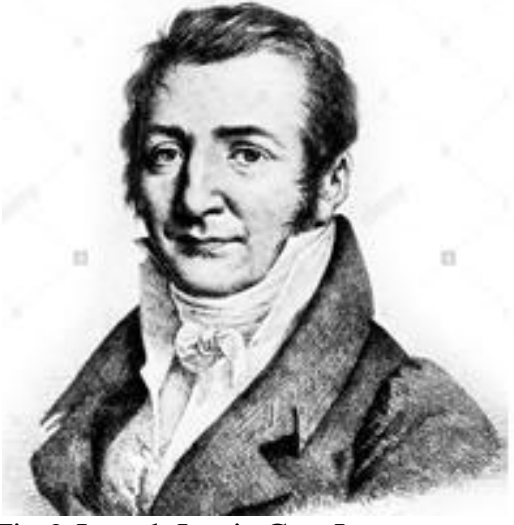

Fig.9 Joseph Louis Gay-Lussac $(1778-1850)$

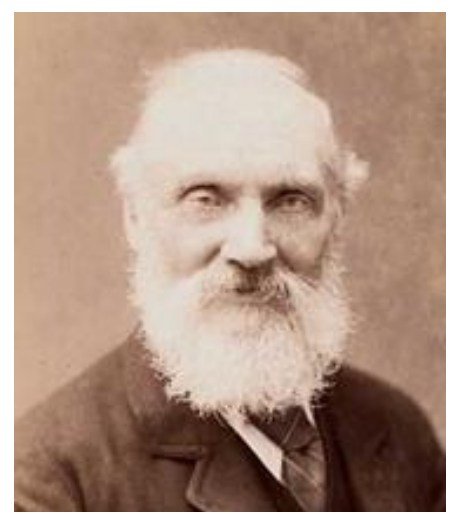

Fig.10 William Thomson (Lord (1824-1907)

(The three stalwarts and the beginners of Absolute Zero)

The constancy of $\alpha$ and $\beta$ is an important milestone in our search for the absolute zero. Heuse and Otto [ ] performed experiments with helium, hydrogen and nitrogen and got the following values for $\alpha$ and $\beta$ :

Gas $\alpha$ $\beta$

$\begin{array}{ccc}\text { Helium } & 0.0036607 & 0.0036609 \\ \text { Hydrogen } & 0.0036611 & 0.0036610 \\ \text { Nitrogen } & 0.0036609 & 0.0036606\end{array}$

From the above, Otto and Heuse got an acceptable overall mean value $\mathbf{0 . 0 0 3 6 6 0 8}$

Equations (2) and (2a) show that the volume and pressure varies linearly with temperature and hence a graph when plotted will be as shown in Fig.11clarifying that the two laws are identical and some authors use both the laws synonymously and name the Gay-Lussac law as second Charle's law. The quantities appearing on the left-side of the graph are some of the requirements for our future work

The extrapolation of the graph meeting the temperature axis on the negative side is either $\mathrm{t}=-\frac{1}{\alpha}{ }^{\circ} \mathrm{C}$ or $\mathrm{t}=-\frac{1}{\beta}{ }^{\circ} \mathrm{C}$ is equal to $-\frac{1}{0.0036608}{ }^{\circ} \mathrm{C}=-273.16^{\circ} \mathrm{C}$.and is known as Absolute Zero. This is just a theoretical value and practical approach to it was next to impossible those days as cooling methods to such extreme values were not known.

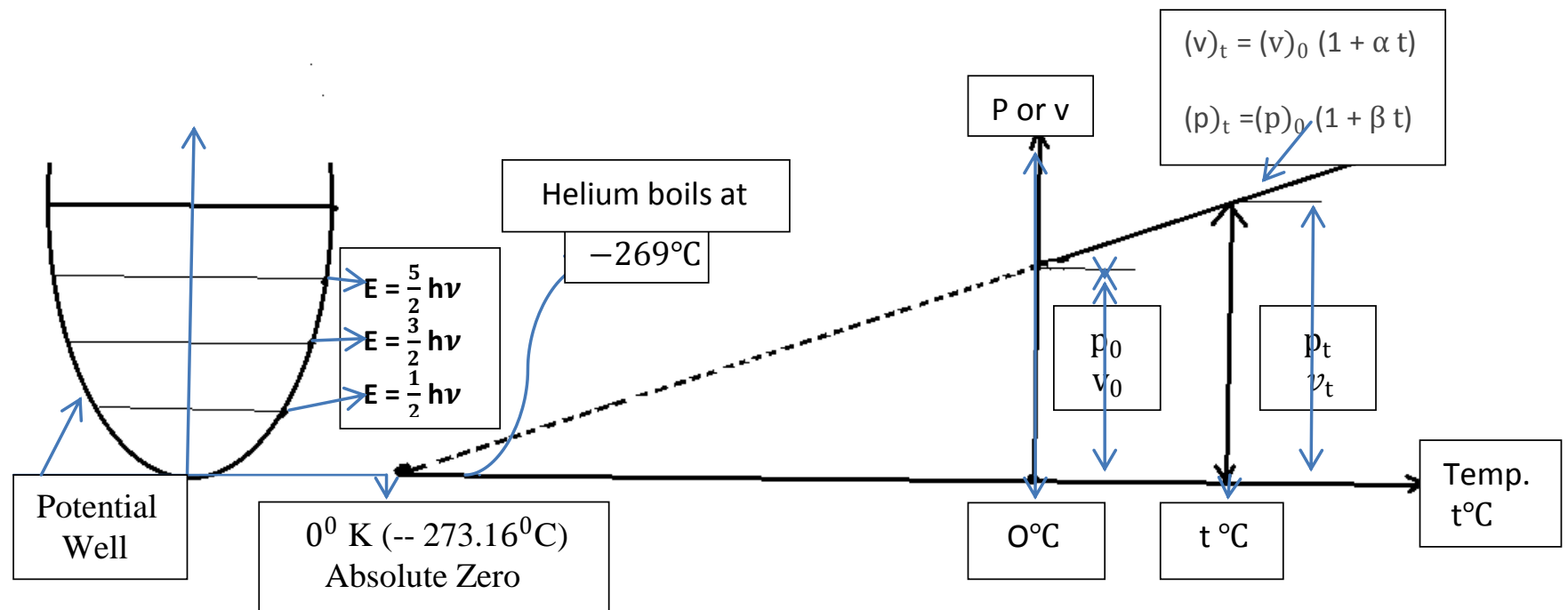

Fig.11. Graphical illustration of Charles and Gay Lussac Laws 


\section{International Advanced Research Journal in Science, Engineering and Technology \\ ISO 3297:2007 Certified}

Vol. 5, Issue 3, March 2018

3.2.The Absolute Zero: The concept of absolute zero was rigorously dealt with by the Scots-Irish mathematical physicist, William Thomson later known as Lord Kelvin (1824-1907) (Fig.10) a real stalwart among all physicists of his time. Before coming to his works and from a historical view point, it is worthwhile to consider one or two earlier workers other than Charles and Gay-Lussac.

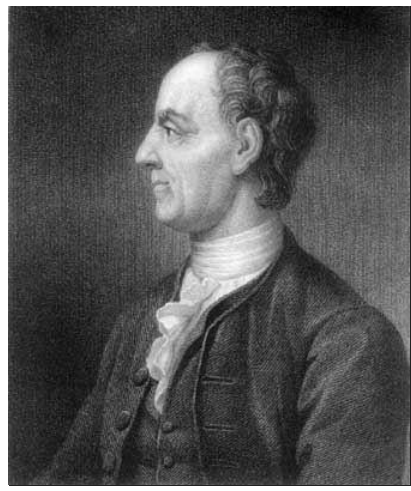

Fig 11 Guillaume Amontons $(1663-1705)$

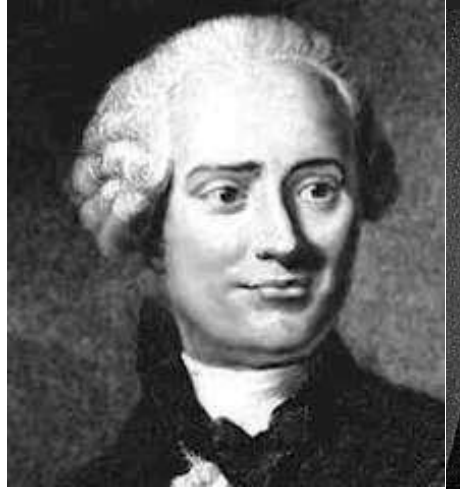

Fig.12 Johann Heinrich Lambert (1728-1777)

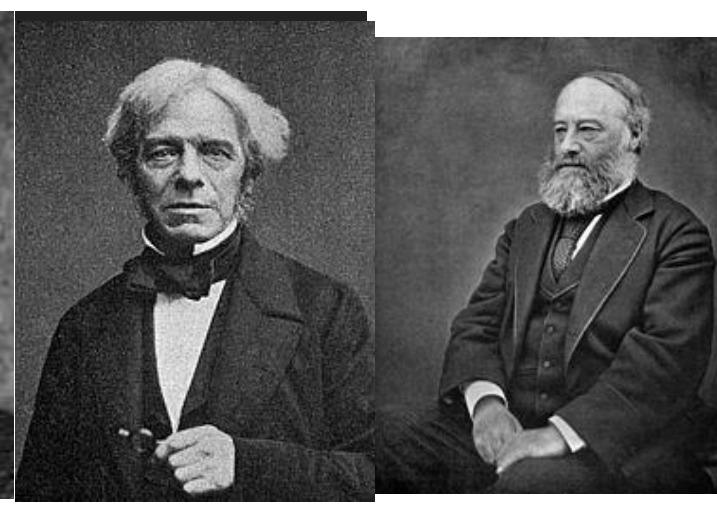

Fig.13 Michael Farad ay Fig.14 James Prescott (1791- 1867) Joule (1818-1889)

The first researcher to predict the existence of absolute zero was the French physicist and instrument inventor, Guillaume Amontons (1663-1705) (Fig.11). He found that sufficient reduction of temperature in a certain quantity of air brought its volume to zero. This happened at a temperature, $-240^{\circ} \mathrm{C}$ some 33.16 degrees less than the correct value.

Johann Henrich Lambert (1728-1777) (Fig.12) was a Swiss physicist and philosopher who proposed an absolute temperature scale based on pressure/temperature relationship of a fixed volume of a gas. Lambert stated that absolute zero was the point when a simple straight line extrapolation reached zero gas pressure and was equal to $-270^{\circ} \mathrm{C}$

\section{STEP - 3}

4.0.The English physicist, Michael Faraday (1791-1867) (Fig.13) in 1823 liquefied chlorine and ammonia and recognized that the chemical change from gas to liquid state radially lowers the temperature

4.1.The Work of Lord Kelvin: Cooling was observed in the famous classical experiment performed jointly by the English physicist and mathematician, James Prescott Joule (1818-1889) (Fig.14) and Lord Kelvin (Fig.10). The experiment, though simple, gained importance in the principles of thermodynamics that led to cooling and absolute zero. The experiment is known by both the names "Joule-Thomson Effect" and "Joule-Kelvin Effect" as Kelvin is a title held by William Thomson. The concept of their experiments is to use some mathematics and obtain effect of cooling and ultimately get the temperature in the absolute scale for the lower fixed point which is the melting point of ice.

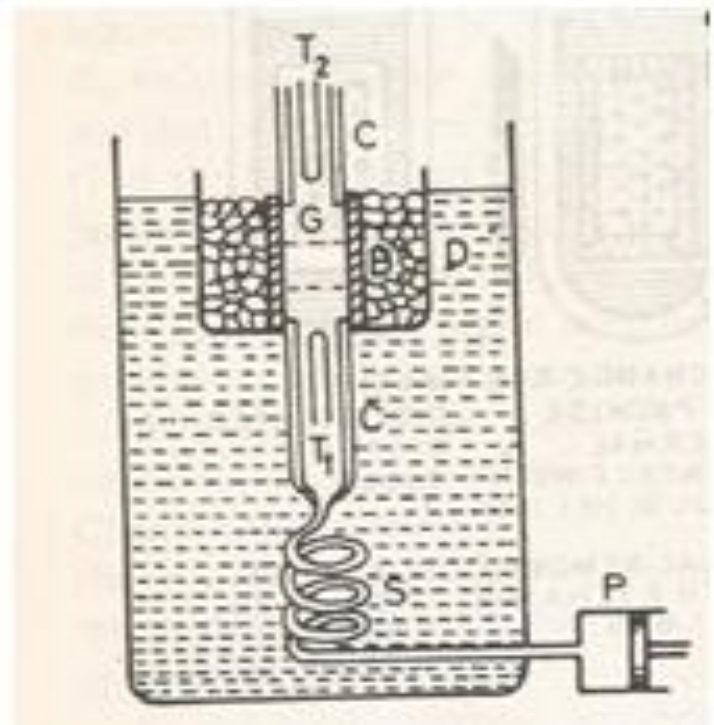

\subsection{The Joule-Thomson Effect:}

The experimental arrangement is shown in Fig.15 [7]. It consists of a porous plug $G$ of silk or cotton wool kept in position between two perforated brass plates and enclosed in a cylindrical wooden box B which is surrounded by a brass case D tightly filled with some good thermal insulator such as cotton wool. The wooden box B is surrounded by a brass vessel D to protect it from coming into contact with water as the whole arrangement is immersed in a water bath so as to maintain constancy of temperature. The box B is fitted on both sides by copper tubes CC. The lower of this is connected to a vacuum pump $\mathrm{P}$ through a copper spiral $\mathrm{S}$ which is also immersed in water so as to maintain the gas at constant temperature before passing through the plug.

The compressed gas is allowed to suffer throttle expansion through the porous plug $\mathrm{G}$.

The Fig.15 The Joule-Thomson Apparatus temperature of the gas on two sides of the plug is measured with platinum thermometers $\mathrm{T}_{1}$ and $\mathrm{T}_{2}$. 


\section{International Advanced Research Journal in Science, Engineering and Technology}

ISO 3297:2007 Certified

Vol. 5, Issue 3, March 2018

The experiment is repeated for various differences of pressure on the two sides of the porous plug. The actual movement of the gas and the principle of operation is shown in Fig.16.[5]

The gas is allowed to stream slowly through the porous plug. The pressures on the two sides of the Plug are $\mathrm{p}_{1}$ and $\mathrm{p}_{2}$ and as per the direction of flow as shown, $\mathrm{p}_{1}$ is greater than $\mathrm{p}_{2}$. The starting point for any of our treatment related to the title of our research paper is the equation of Boyle's law, $\mathrm{P} V=$ Constant at constant temperature for a certain quantity of gas. The constant being a product of the universal gas constant $\mathrm{R}$ and the absolute temperature $\mathrm{T}$ in which case we have the equation,

$$
\mathrm{PV}=\mathrm{R} \mathrm{T}
$$

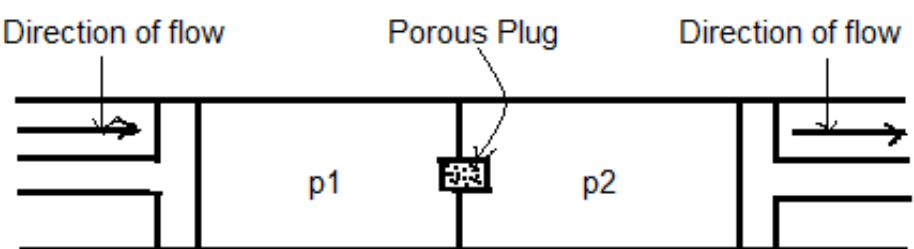

Fig.16 Illustrative diagram for the Joule-Thomson Effect

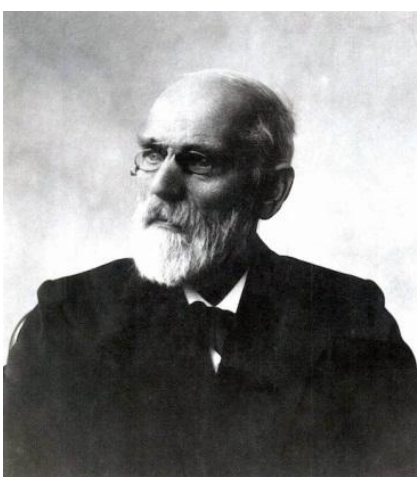

Fig. 17Van der Waals (1837-1923)

The equation (4) is a simple equation of state which was modified or rather corrected by a Dutch theoretical physicist, Van der Waals (1837-1923) (Fig.17) who was devoted to thermodynamics of gases by considering the intermolecular forces and the volume occupied by the molecules themselves. By theoretical considerations he added a correction term, $\frac{a}{\mathrm{~V}^{2}}$ where $\mathrm{a}$ is a constant to the pressure $\mathrm{p}$ and subtracted a constant $\mathrm{b}$ from the volume $\mathrm{V}$ so that the equation (4) becomes:

$$
\left(\mathrm{p}+\frac{a}{\mathrm{~V}^{2}}\right)(\mathrm{V}-\mathrm{b})=\mathrm{RT}
$$

This is the famous equation of Van der Waals and the constants a and b are appropriate to a gram-molecule (unit mass) of gas. If $V_{1}$ and $V_{2}$ are the volumes corresponding to the pressures $p_{1}$ and $p_{2}$ respectively and assuming there is no loss of heat, the net work done by the gas per unit mass in the apparatus is $p_{2} V_{2}-p_{1} V_{1}$. Now, taking into consideration of Van der Waal's inter molecular forces, the work done by the gas against the attractive forces of the molecules is equal to:

$$
\int_{\mathrm{V}_{1}}^{\mathrm{V}_{2}}\left(\frac{a}{\mathrm{~V}^{2}}\right) \mathrm{dV}
$$

where the quantity in the bracket in the integrand is the Van der correction term for the pressure as per equation (5). The value of the integration is $\left(-\frac{a}{\mathrm{~V}_{2}}+\frac{a}{\mathrm{~V}_{1}}\right)$ and hence the total work done $\mathrm{W}$ by the gas is therefore

$$
\mathrm{W}=\mathrm{p}_{2} \mathrm{~V}_{2}-p_{1} \mathrm{~V}_{1}-\frac{a}{\mathrm{~V}_{2}}+\frac{a}{\mathrm{~V}_{1}}
$$

Expanding the Van der Waal's equation (5) we get

$$
\begin{aligned}
\mathrm{pV} & -\mathrm{pb}+\frac{\mathrm{a}}{\mathrm{V}}-\frac{\mathrm{a} b}{\mathrm{~V}^{2}}=\mathrm{R} \mathrm{T} \\
\therefore \mathrm{p} \mathrm{V} & =\mathrm{R} \mathrm{T}+\frac{\mathrm{a} b}{\mathrm{~V}^{2}}-\frac{\mathrm{a}}{\mathrm{V}}+\mathrm{p} \mathrm{b} \\
& =\mathrm{RT}+\mathrm{p} \mathrm{b}-\mathrm{a}\left(\frac{1}{\mathrm{~V}}-\frac{\mathrm{b}}{\mathrm{V}^{2}}\right) \\
& =\mathrm{RT}+\mathrm{p} \mathrm{b}-\mathrm{a}\left(\frac{\mathrm{p}}{\mathrm{RT}}-\frac{\mathrm{p}^{2} \mathrm{~b}}{(\mathrm{RT})^{2}}\right)
\end{aligned}
$$

where we have substituted $\frac{\mathrm{R} T}{\mathrm{P}}$ for $\mathrm{V}$ from the equation $\mathrm{P} V=\mathrm{R} T$. As the Van der Waals constants a and $\mathrm{b}$ being small, their product will be still smaller and hence they can be neglected and hence the above equation takes the form:

$$
\mathrm{p} \mathrm{V}=\mathrm{RT}+\mathrm{p} b-\frac{\mathrm{ap}}{\mathrm{RT}}
$$

In the equation (6) for the work done $\mathrm{W}$, for the first two terms $\mathrm{p}_{2} \mathrm{~V}_{2}-p_{1} \mathrm{~V}_{1}$, substitute quantities from equation (7) appropriately and for the remaining two terms where the volumes $\mathrm{V}$ appear in the denominator, substitute from equation, $\mathrm{P} \mathrm{V}=\mathrm{R} \mathrm{T}$ so that 


$$
\begin{aligned}
\mathrm{W} & =\mathrm{RT}-\frac{a \mathrm{p}_{2}}{\mathrm{RT}}+\mathrm{b} \mathrm{p}_{2}-\mathrm{RT}+\frac{\mathrm{a} \mathrm{p}_{1}}{\mathrm{RT}}-\mathrm{b} \mathrm{p}_{1}-\frac{\mathrm{a} \mathrm{p}_{2}}{\mathrm{RT}}+\frac{\mathrm{a} \mathrm{p}_{1}}{\mathrm{RT}} \\
& =\mathrm{p}_{1}\left(\frac{\mathrm{a}}{\mathrm{RT}}-\mathrm{b}+\frac{\mathrm{a}}{\mathrm{RT}}\right)-\mathrm{p}_{2}\left(\frac{\mathrm{a}}{\mathrm{RT}}-\mathrm{b}+\frac{\mathrm{a}}{\mathrm{RT}}\right) \\
\therefore \quad \mathrm{W} & =\left(\frac{2 \mathrm{a}}{\mathrm{RT}}-\mathrm{b}\right)\left(\mathrm{p}_{1}-\mathrm{p}_{2}\right) \ldots \ldots \ldots \ldots \ldots \ldots \ldots \ldots \ldots \ldots \ldots \ldots
\end{aligned}
$$

The quantity $\left(\mathrm{p}_{1}-\mathrm{p}_{2}\right)$ is necessarily positive. The heat supplied, if any, is positive. if $\frac{2 \mathrm{a}}{\mathrm{R} T}$ is greater than $\mathrm{b}$. As no heat is supplied, the experiments of Joule and Kelvin show that there is cooling at ordinary temperatures in all cases except hydrogen. But, however, when hydrogen is cooled below $-80^{\circ} \mathrm{C}$ and allowed to pass through the apparatus, a cooling was observed even in hydrogen.

When $\frac{2 \mathrm{a}}{\mathrm{RT}}$ is equal to $\mathrm{b}$, the sign of the Joule-Kelvin effect changes at a temperature $\mathrm{T}_{\mathrm{i}}=\frac{2 \mathrm{a}}{\mathrm{R} \mathrm{b}}$ called the Inversion Temperature.

We cannot stop at this stage [ ] till we get a value for the lower fixed point which is the melting point of ice. There is a jugglery of suffixes. Let suffix 1 refer to the high-pressure and suffix 2 to the low-pressure side of the plug, the net work done by external forces on unit mass of gas is from equation (6)

$$
\Delta \mathrm{w}=\mathrm{p}_{1} \mathrm{v}_{1}-\mathrm{p}_{2} \mathrm{v}_{2}
$$

Let $\mathrm{u}_{1}$ be the internal energy of unit gas before and $\mathrm{u}_{2}$ after passing through the plug so that

$$
\Delta \mathrm{u}=\mathrm{u}_{2}-\mathrm{u}_{1}
$$

We have the first law of thermodynamics, $\Delta \mathrm{u}=\Delta \mathrm{q}+\Delta \mathrm{w}$ and as no heart enters the gas, we can set $\Delta \mathrm{q}=0$ so that $\Delta \mathrm{u}=\Delta \mathrm{w}$. That is,

Iwhich we write in the form

$$
\begin{aligned}
& \mathrm{u}_{2}-\mathrm{u}_{1}=\mathrm{p}_{1} \mathrm{v}_{1}-\mathrm{p}_{2} \mathrm{v}_{2} \text { from which } \\
& \mathrm{u}_{2}+\mathrm{p}_{2} \mathrm{v}_{2}=\mathrm{u}_{1}+\mathrm{p}_{1} \mathrm{v}_{1}
\end{aligned}
$$

$$
\Delta(\mathrm{u}+\mathrm{p} v)=0
$$

Expanding (11) we get

$$
\Delta \mathrm{u}+\mathrm{p} \Delta \mathrm{v}+\mathrm{v} \Delta \mathrm{p}=0
$$

But, $\Delta \mathrm{u}+\mathrm{p} \Delta \mathrm{v}=\mathrm{T} \Delta \mathrm{S}$ where $\mathrm{S}$ is the entropy. Therefore,

$$
\mathrm{T} \Delta \mathrm{S}+\mathrm{v} \Delta \mathrm{p}=0
$$

Further, $\Delta \mathrm{S}=\left(\frac{\partial \mathrm{S}}{\partial \mathrm{T}}\right)_{\mathrm{p}} \Delta \mathrm{T}+\left(\frac{\partial \mathrm{S}}{\partial \mathrm{p}}\right)_{\mathrm{T}} \Delta \mathrm{p}$ and substitute this in the above equation to get

$$
\begin{array}{r}
\mathrm{T}\left[\left(\frac{\partial \mathrm{S}}{\partial \mathrm{T}}\right)_{\mathrm{p}} \Delta \mathrm{T}+\left(\frac{\partial \mathrm{S}}{\partial \mathrm{p}}\right)_{\mathrm{T}} \Delta \mathrm{p}\right]+\mathrm{v} \Delta \mathrm{p}=0 \\
\therefore \mathrm{T}\left(\frac{\partial \mathrm{S}}{\partial \mathrm{T}}\right)_{\mathrm{p}} \Delta \mathrm{T}+\Delta \mathrm{p}\left[\mathrm{v}+\mathrm{T}\left(\frac{\partial \mathrm{S}}{\partial \mathrm{p}}\right)_{\mathrm{T}}\right]=0
\end{array}
$$

But, the specific heat at constant pressure, $c_{p}=\left(\frac{\partial q}{\partial T}\right)_{p}=T\left(\frac{\partial S}{\partial T}\right)_{p}$ and from one of the Maxwell's thermodynamic relation, $\left(\frac{\partial \mathrm{S}}{\partial \mathrm{p}}\right)_{\mathrm{v}}=-\left(\frac{\partial \mathrm{v}}{\partial \mathrm{T}}\right)_{\mathrm{p}}$ and combining all these the equation (14) becomes

$$
\begin{aligned}
\mathrm{c}_{\mathrm{p}} \Delta \mathrm{T} & +\left[\mathrm{v}-\mathrm{T}\left(\frac{\partial \mathrm{v}}{\partial \mathrm{T}}\right)_{\mathrm{p}}\right] \Delta \mathrm{p}=0 \\
\therefore \Delta \mathrm{T} & =\left[\frac{\mathrm{T}\left(\frac{\partial \mathrm{v}}{\partial \mathrm{T}}\right)_{\mathrm{p}}-\mathrm{v}}{\mathrm{c}_{\mathrm{p}}}\right] \Delta \mathrm{p} \\
\text { or } \quad \frac{\Delta \mathrm{T}}{\Delta \mathrm{p}} & =\frac{\mathrm{T}\left(\frac{\partial \mathrm{v}}{\partial \mathrm{T}}\right)_{\mathrm{p}}-\mathrm{v}}{\mathrm{c}_{\mathrm{p}}} \ldots \ldots \ldots
\end{aligned}
$$

This is the final equation for the Joule-Kelvin effect.

Except $\Delta \mathrm{p}$ and $\mathrm{v}$, we know nothing about the other quantities in the above equation specially the whereabouts of the so-called absolute temperature $\mathrm{T}$. Let us assume to possess an empirical thermometer measuring a temperature $\mathrm{T}^{\prime}$ such that the thermodynamic temperature $\mathrm{T}$ is a function of $\mathrm{T}^{\prime}$. Thus the quantity in brackets in the numerator of equation ( ) can be written as

$\frac{\partial \mathrm{v}}{\partial \mathrm{T}}=\frac{\partial \mathrm{v}}{\partial \mathrm{T}^{\prime}} \frac{d \mathrm{~T}^{\prime}}{\mathrm{dT}}$ and for other quantities, $\Delta \mathrm{T}=\Delta \mathrm{T}^{\prime} \frac{\mathrm{dT}}{\mathrm{dT}^{\prime} .}$ and $\mathrm{c}_{\mathrm{p}}=\left(\frac{\mathrm{dq}}{\mathrm{dT}}\right)_{\mathrm{p}}=\left(\frac{\mathrm{dq}}{\mathrm{dT}}\right)_{\mathrm{p}} \frac{d \mathrm{~T}^{\prime}}{\mathrm{dT}}=\left(\mathrm{c}_{\mathrm{p}}\right)^{\prime} \frac{d \mathrm{~T}^{\prime}}{\mathrm{dT}}$.

Substituting these values in equation (15) we obtain $\Delta \mathrm{T}^{\prime}$ the temperature measured on the empirical thermometer for the Joule- Kelvin effect, 


$$
\frac{\Delta \mathrm{T}^{\prime}}{\Delta \mathrm{p}}=\frac{\left[\mathrm{T}\left(\frac{\partial \mathrm{v}}{\partial \mathrm{T}^{\mathrm{T}}}\right) \mathrm{p} \frac{d \mathrm{~T}^{\prime}}{\mathrm{dT}}-\mathrm{v}\right]}{\left(\mathrm{c}_{\mathrm{p}}\right)^{\prime}}
$$

This can be re-arranged as $\frac{\mathrm{T}}{\mathrm{dT}}\left(\frac{\partial \mathrm{v}}{\partial \mathrm{T}^{\prime}}\right)_{\mathrm{p}} \mathrm{dT}^{\prime}-\mathrm{v}=\left(\mathrm{c}_{\mathrm{p}}\right)^{\prime} \frac{\Delta \mathrm{T}^{\prime}}{\Delta \mathrm{p}}$

$$
\text { or } \frac{\mathrm{T}}{\mathrm{dT}}=\frac{\left[\left(\mathrm{c}_{\mathrm{p}}\right)^{\prime} \frac{\Delta \mathrm{T}^{\prime}}{\Delta p}+\mathrm{v}\right]}{\left(\frac{\partial \mathrm{v}}{\partial \mathrm{T}}\right) \mathrm{p} \mathrm{dT}^{\prime}} \text {, that is, } \frac{\mathrm{dT}}{\mathrm{T}}=\frac{\left(\frac{\partial \mathrm{v}}{\partial \mathrm{T}^{\prime}}\right) \mathrm{p} \mathrm{dT}^{\prime}}{\left[\left(\mathrm{c}_{\mathrm{p}}\right)^{\prime} \frac{\Delta \mathrm{T}^{\prime}}{\Delta p}+\mathrm{v}\right]}
$$

Now, writing $\mu^{\prime}$ for $\frac{\Delta \mathrm{T}^{\prime}}{\Delta \mathrm{p}}$, we get

$$
\frac{\mathrm{dT}}{\mathrm{T}}=\frac{\left(\frac{\partial \mathrm{v}}{\partial \mathrm{T}}\right) \mathrm{p}}{\left[\left(c_{\mathrm{p}}\right)^{\prime} \mu^{\prime}+\mathrm{v}\right]} \mathrm{dT}^{\prime}
$$

Integrating and writing $\mathrm{T}_{0}$ for the melting point of ice on the absolute scale and $\mathrm{T}_{0}^{\prime}$ for this temperature on the empirical scale, the equation (16) becomes

$$
\log \left(\frac{\mathrm{T}}{\mathrm{T}_{0}}\right)=\int_{\mathrm{T}_{0}^{\prime}}^{\mathrm{T}}\left(\frac{\left(\frac{\partial \mathrm{v}}{\partial \mathrm{T}^{\prime}}\right) \mathrm{p}}{\left[\left(\mathrm{c}_{\mathrm{p}}\right)^{\prime} \mu^{\prime}+\mathrm{v}\right]}\right) \mathrm{dT}^{\prime}
$$

All the quantities under the integral sign can be expressed as empirical functions of the temperature $\mathrm{T}^{\prime}$.

We now define the interval between melting point of ice and boiling point of water on the absolute thermodynamic scale as 100 degrees. If then $\mathrm{T}_{1}^{\prime}$ is the measure of the boiling point of water on the empirical practical scale, we have

$$
\log \left(\frac{\mathrm{T}_{0}+100}{\mathrm{~T}_{0}}\right)=\int_{\mathrm{T}_{0}^{\prime}}^{\mathrm{T}_{1}^{\prime}}\left(\frac{\left(\frac{\partial \mathrm{v}}{\partial \mathrm{T}}\right) \mathrm{p}_{\mathrm{p}}}{\left[\left(\mathrm{c}_{\mathrm{p}}\right)^{\prime} \mu^{\prime}+\mathrm{v}\right]}\right) \mathrm{dT}^{\prime} \ldots \ldots \ldots \ldots \ldots \ldots
$$

This equation shows how $\mathrm{T}_{0}$ the temperature of the melting point of ice on the absolute thermodynamic scale can be determined from measurements of thermal properties of any gas between the melting point of ice and boiling point of water. Once $\mathrm{T}_{0}$ has been determined, the value of any other temperature can be determined from the equation (17)

The integral in equation (17) can be solved graphically or otherwise and the trivial solution carried out by J.R. Roebuck [5] in the year 1936. He used three different gases air, helium and nitrogen in the Joule-Kelvin's Porous Plug experiment and got values for $\mathrm{T}_{0}$ as $273.158,273.168$ and 273.125 respectively and the most probable value was found to be $273.16 \pm 0.02$. The author suggested the use of a helium mixture to give the melting point of ice precisely as the reciprocal of the coefficient of its volume expansion.

Thus, the absolute zero and absolute scale have been theoretically established by Lord Kelvin in 1848. The same results were arrived at in 1852 by using second law of thermodynamics wherein it was found that the efficiency of a heat engine turning out to be unity which ultimately led to the un-attainability of absolute zero. In the year 1870 Ludwig Boltzmann, the genius of disorder using the concept of entropy arrived at similar results.

The intercept $-273.16^{\circ} \mathrm{C}$ in Fig. and the theoretically obtained value from the Joule-Thomson effect $+273.16 \pm 0.02$ ${ }^{\circ} \mathrm{C}$, compels us to add -273 the decimal 0.16 being ignored. Hence if we denote $\mathrm{t}$ as the temperature in Celsius and $\mathrm{T}$ the temperature in the new absolute scale, then

$\mathrm{T}$ degree Kelvin $=\mathrm{t}$ degree Celsius +273 .

That is, $\mathrm{T}^{0} \mathrm{~K}=\mathrm{t}^{\circ} \mathrm{C}+273$

As capital letter $\mathrm{K}$ is usually meant for the Kelvin scale, ${ }^{0} \mathrm{~K}$ and ${ }^{\circ} \mathrm{C}$ are not written. Hence,

$$
\mathrm{T}=\mathrm{t}+273
$$

and melting point of ice $=0+273=273 \mathrm{~K}$ and boiling point of water $=373 \mathrm{~K}$ and

$$
\text { Absolute Zero }=-273+273=0 \mathrm{~K}
$$

$0 \mathrm{~K}$ was just an identification and attaining that temperature was really a herculean task as effective cooling methods were not known at his time.

\section{STEP - 4}

5.1. Production of low temperatures: Various methods of producing low temperatures have been attempted by many workers in the $19^{\text {th }}$ and $20^{\text {th }}$ centuries. The choice of material to be cooled is of importance. Solids and liquids, because of their atomic structure, are not suitable and hence we are compelled to select some ideal gas light and with a very simple atomic structure.

5.2.The Choice of Helium: Helium $(\mathrm{He}-4)$ has won the race in the selection because of its following unique properties: Low boiling point, low density, low solubility, high thermal conductivity and above all it is an inert gas. It will be shown later that when helium is used in the process of cooling, it sometimes loses one neutron from its nucleus and becomes lighter isotope, i.e Helium-3. The atomic structures of He-4 and He-3 are shown in Fig.18 


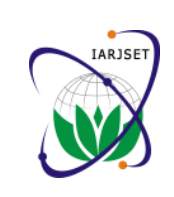

IARJSET

\section{International Advanced Research Journal in Science, Engineering and Technology}

ISO 3297:2007 Certified

Vol. 5, Issue 3, March 2018

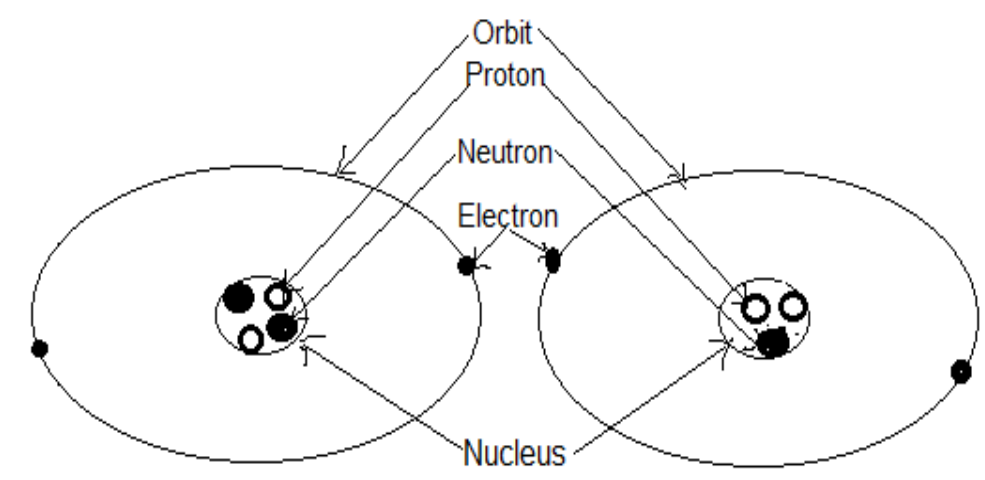

Helium-4

Atomic No. 2 Atomic Wt. 4.002602

Critical Temp. $5.2 \mathrm{~K}$

Boiling point at 1 Atm. $4.2 \mathrm{~K}$

Helium-3

Atomic No.2 Atomic Wt. 3.016

Critical Temp. $3.3 \mathrm{~K}$

Boiling point at 1 Atm. $3.2 \mathrm{~K}$

Density at Boiling Point at $1 \mathrm{Atm}=0.125 \frac{\mathrm{gm}}{\mathrm{cc}}$.

Fig.18 Diagram illustrating the structure and pruperties of Helium

The heavier helium-4 has altogether 6 fundamental particles. ( 2 neutrons, 2 protons in the nucleus and 2 electrons orbiting around the nucleus. On the other hand, Helium-3 is made up of only 5 particles ( 2 protons and 1 neutron in the nucleus, and 2 orbiting electrons.

5.3.The Turning Point: On 10 July 1908, the Dutch physicist, Heike Kamerlingh Onnes (1853-1926) (Fig.19) successfully liquefied helium in a laboratory at the university of Leiden, Netherlands and was awarded the 1913 Nobel Prize in Physics. A picture of the Physics laboratory which became the "Coldest Place on Earth" on the date mentioned is shown in Fig. 21.

The principle of operation in obtaining liquid helium is shown fig.20 [5]. Cylinders A Contain about 200 liters of liquid helium. The compressor BB is used to compress the gas even up to 100 atmospheres. The gas passes through narrow tube $\mathrm{CEFG}$ and expands through the valve $\mathrm{H}$ and enters the vacuum flask. The gas after expansion passes through the spiral $\mathrm{G}$ and cools the oncoming gas. The gas then again enters the compressor BB through the tube K. The cycle gets repeated. The liquid helium gets collected in the vessel inside the flask. The spirals $\mathrm{E}$ and $\mathrm{F}$ are arranged in a vessel $\mathrm{L}$ containing liquid hydrogen boiling at $-258^{\circ} \mathrm{C}$. The pump $\mathrm{M}$ regulated the temperature of liquid hydrogen. The vessel in which liquid helium gets collected is surrounded by liquid hydrogen contained in a vacuum vessel containing liquid air.The entire operation has been carried out with due care and the results obtained are very satisfactory Onnes could attain the critical temperature of helium which is $-268^{\circ} \mathrm{C}$, even though later results showed $-269^{\circ} \mathrm{C}$. Which is just 4 degrees above absolute zero. Onnes repeated his experiments in 1911 using liquid mercury and could attain temperatures as low as $0.84 \mathrm{~K}$.

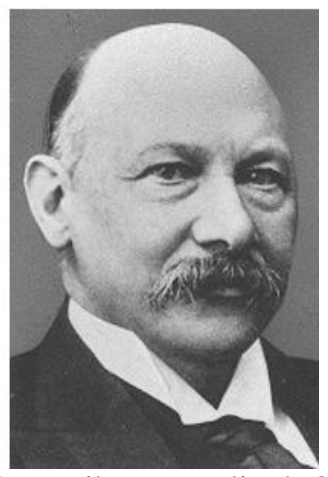

Fig19. Heike Kamerlingh Onnes (1853-1926)

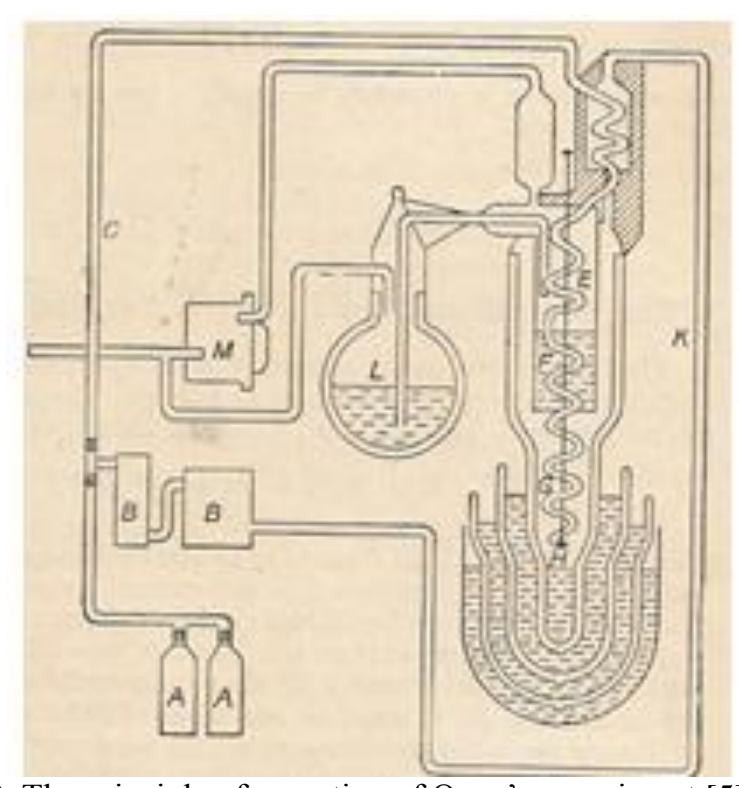

Fig.20 The principle of operation of Onne's experiment [5] 


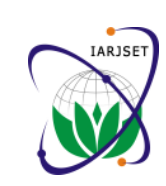

IARJSET

\section{International Advanced Research Journal in Science, Engineering and Technology}

ISO 3297:2007 Certified

Vol. 5, Issue 3, March 2018

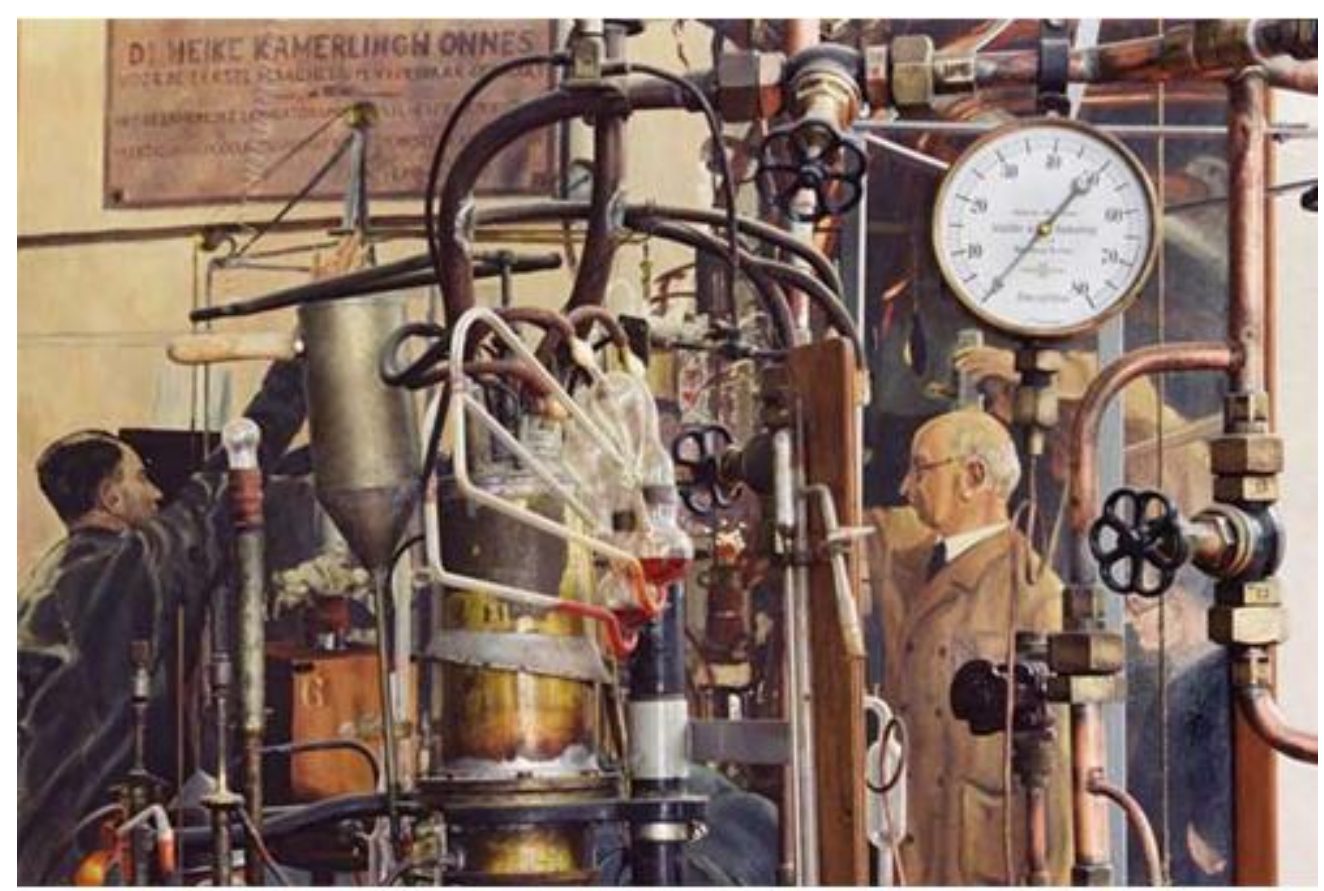

Fig.21 Heike Kamerlingh Onnes at work in his laboratory at Leiden Netherlands

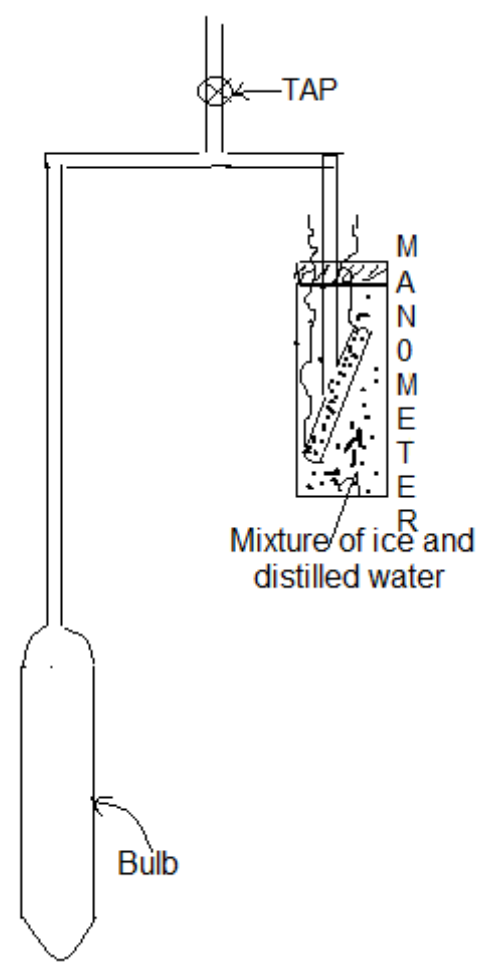

Fig.22 Experimental arrangement of Keesom and his co-workers [5]

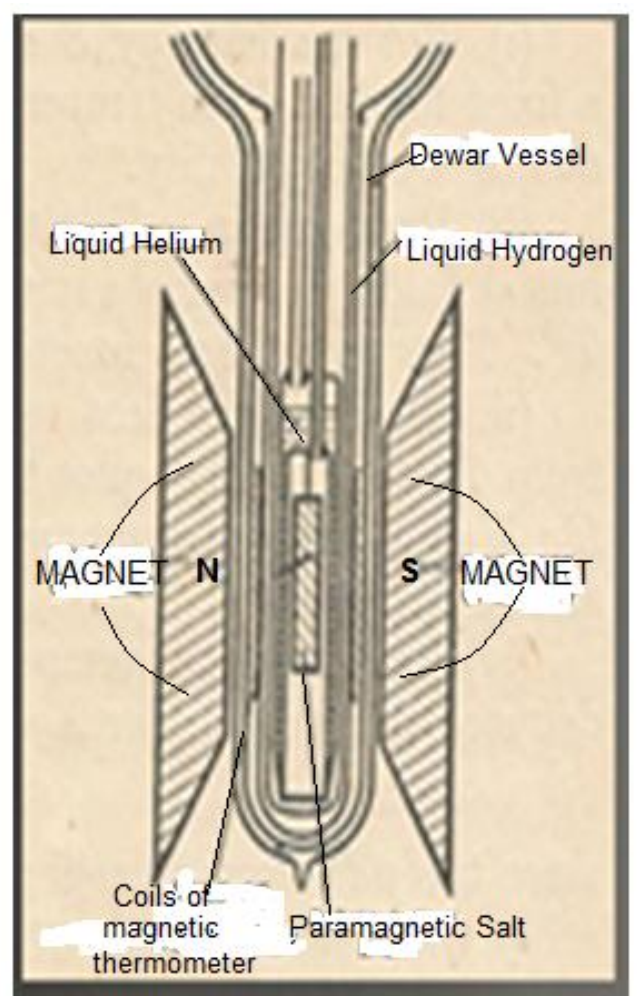

Fig. 23 The apparatus of Kurti and Simon for adiabatic demagnetization [5]

5.4.Temperatures below 5K [5]: keesom and his co-workers have determined the vapor pressure of helium between temperatures $4.899 \mathrm{~K}$ and $0.844 \mathrm{~K}$. The arrangement used by them is shown in Fig.22 The bulb B was connected by a capillary tube to the calibrated hot-wire manometer used for measuring the pressure. It is kept immersed in a mixture of ice and distilled water. The purpose of the tap is to allow helium 


\section{International Advanced Research Journal in Science, Engineering and Technology}

ISO 3297:2007 Certified

Vol. 5, Issue 3, March 2018

Table-1[5]

\begin{tabular}{|c|c|c|c|c|c|c|c|c|c|c|c|}
\hline No. & $\begin{array}{c}\text { Temp. } \\
\mathrm{K}\end{array}$ & $\begin{array}{c}\text { Vapor } \\
\text { Pre. } \\
\mathrm{cm} \text { of } \\
\mathrm{Hg}\end{array}$ & No & $\begin{array}{c}\text { Temp. } \\
\mathrm{K}\end{array}$ & $\begin{array}{l}\text { Vapor } \\
\text { Pre. } \\
\mathrm{cm} \text { of } \\
\mathrm{Hg}\end{array}$ & No & $\begin{array}{c}\text { Temp. } \\
\mathrm{K}\end{array}$ & $\begin{array}{l}\text { Vapor } \\
\text { Pre. } \\
\mathrm{cm} \text { of } \\
\mathrm{Hg}\end{array}$ & No & $\begin{array}{c}\text { Temp. } \\
\mathrm{K}\end{array}$ & $\begin{array}{l}\text { Vapor } \\
\text { Pre. } \\
\mathrm{cm} \text { of } \\
\mathrm{Hg}\end{array}$ \\
\hline 1 & 4.899 & 132.9 & 5 & 2.636 & 10.00 & 9 & 1.538 & 0.500 & 13 & 1.055 & 0.0250 \\
\hline 2 & 4.219 & 76.00 & 6 & 2.298 & 5.00 & 10 & 1.393 & 0.250 & 14 & 0.960 & $0 . .0100$ \\
\hline 3 & 3.795 & 50.00 & 7 & 2.013 & 2.50 & 11 & 1.237 & 0.1000 & 15 & 0.899 & 0.0050 \\
\hline 4 & 3.218 & 25.00 & 8 & 1.714 & 1.000 & 12 & 1.139 & 0.0500 & 16 & 0.844 & 0.0025 \\
\hline
\end{tabular}

when required and close when not required. Fast condensation pumps were used for the measurement of various reduced pressures of helium. The vapor pressure was measured by means of a McLeod gauge.

The temperatures were measured by a helium gas thermometer with helium at a low pressure. The results are tabulated in Table No.1

5.5. Critical Study on behavior of Helium : As the cooling went on up to $0.844 \mathrm{~K}$, physicists were interested to study in detail the behavior of helium at very low temperatures even in the viscinity of absolute zero. By helium we mean He-4 which is in abundance, but its isotope, He-3 is also formed in traces during the cooling process. The structure of these two heliums is shown in Fig.18 and the phase diagram for helium is shown in Fig.24 [5]. It is more a double point than a triple point as formation of solid helium is rule out. Helium becomes a solid with considerable efforts of applying a pressure of 30
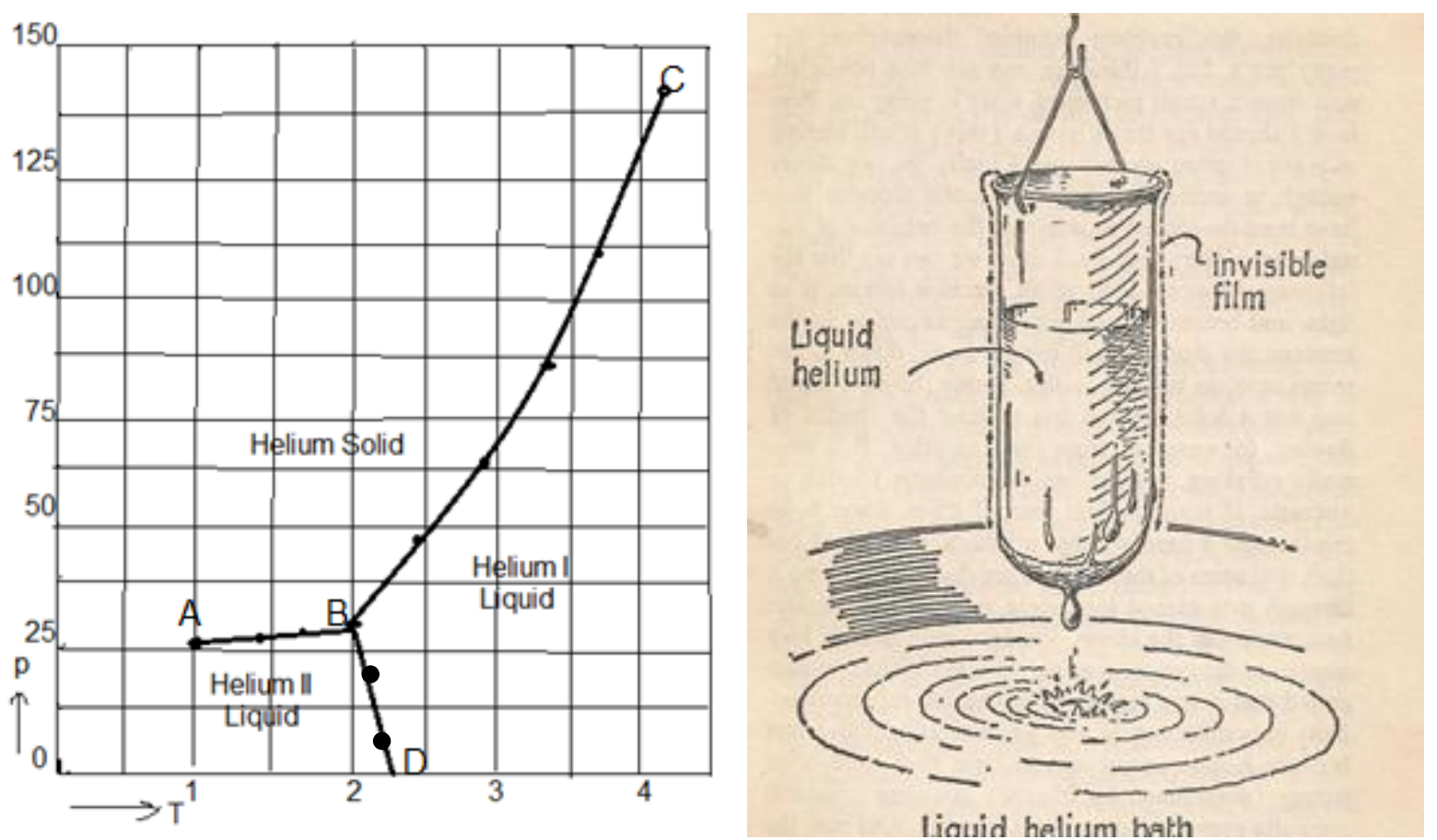

Fig.24 The Phase diagram for Helium [5]

Fig.25 Behavior of Helium as a superfluid [3]

atmospheres at $1 \mathrm{~K}$. Along with the literature that follows, I would request readers to put a glance over the graph of Fig.11 given earlier with more attention to the area near absolute zero in the graph. Neither pressure nor volume becomes zero as assumed in the days of Charles and Gay Lussac. What prevents helium from solidification are two basic concepts of Quantum Mechanics: The zero point energy and the Uncertainty Principle of Heisenberg. The zero point energy, $\frac{1}{2} \mathrm{~h} v$ has to be there and an isolated solid with no absolute thermal motion is ruled out. At a temperature of about $2.2 \mathrm{~K}$ or to be exact $2.186 \mathrm{~K}$, there is a phase change. Above this temperature, Helium Liquid-I is formed and below that temperature Helium Liquid-II is formed. When one looks at the nature of the curves in the graph, it looks like a magnified Greek letter Lambda $(\lambda)$ and hence this temperature is called the Lambda Point of Helium. The behavior of helium near absolute zero, Mac Donald [3] on p.93 compares a genius, a mad man and a common man, makes interesting reading. Below Lambda point. Helium becomes a superfluid and starts flowing without resistance or friction. If a beaker containing superfluid helium is lifted out from the liquid, it will get emptied by a fine invisible film which covers the entire beaker as shown in Fig.25 [3]. 


\section{International Advanced Research Journal in Science, Engineering and Technology}

ISO 3297:2007 Certified

Vol. 5, Issue 3, March 2018

From the point of view of Quantum Mechanics, a cluster of helium-4 atoms are Bosons obeying Bose-Einstein statistics whereas Helium-3 atoms are Fermions obeying Fermi-Dirac statistics. When we consider Symmetry and Parity, He-3 and He-4 are asymmetrical and hence behave differently.

5.6. OtherMethods of Cooling: As one has to approach absolute zero, the methods we have dealt with will not serve any purpose. Among the two methods of recent origin are Masgnetic Cooling and Laser Cooling

5.6.1Magnetic Cooling or Adiabatic Demagnetization: Debye and Giauque [3\&5] in 1927 suggested that very low temperatures may be produced by adiabatically demagnetizing paramagnetic salts to liquid helium temperatures. An apparatus designed by Kurti and Simon is schematicaly shown in

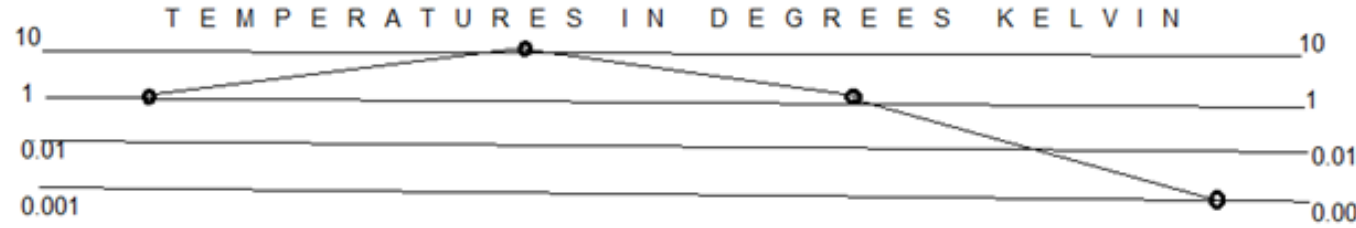

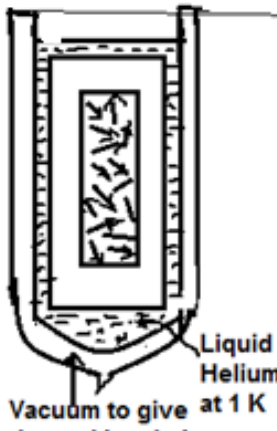

thermal insulation

(a) System isolated

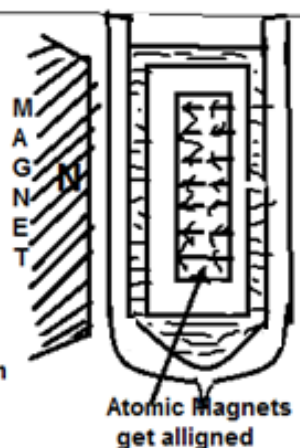

(b) Work done on the system by Magnet

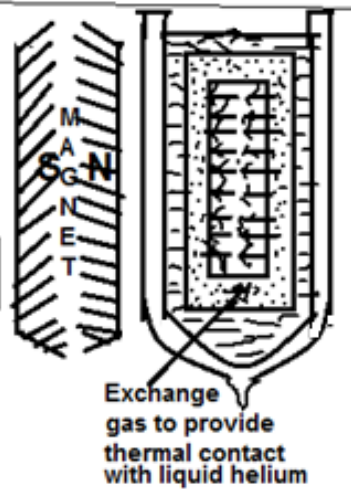

(c) Heat removed with Exchange gas

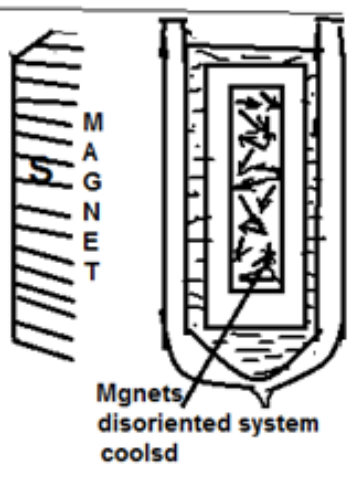

(d) System isolated. Magnet removed

Fig 26 Various stages of cooling in the process of adiabatic demagnetization [3]

Fig.23. Among the various paramagnetic salts, iron ammonium alum $\mathrm{FeNH}_{4}\left(\mathrm{SO}_{4}\right)_{2} 12 \mathrm{H}_{2} \mathrm{O}$ is suspended in a vessel surrounded by liquid helium boiling under reduced pressure. When the magnetic field is switched on, the temperature of the salt rises, but the heat is absorbed by the helium gas surrounding it and the salt in the magnetic field is at the temperature of the liquid helium. The helium gas is now pumped away so that the salt is isolated and immediately the magnetic field is removed. This sudden action abruptly brings down the temperature of the salt. A magnetic thermometer with a primary and secondary coil in conjunction with an alternating current bridge is used to measure the magnetic susceptibility $\chi$ of the salt. Following Curie's law, $\chi \mathrm{T}=$ constant, if $\mathrm{T}_{1}$ is the temperature at a known value of $\chi_{1}$, the susceptibility $\chi_{2}$ after cooling to a temperature $\mathrm{T}$ is given by

$$
\mathrm{T}=\left(\frac{\chi_{1}}{\chi_{2}}\right) \mathrm{T}_{1}
$$

As fig. appears to be congested, a self-explanatory diaghram (Fig. 26) is given by Mac Donald [3] wherein he talks of "Squeezing out" magnetic disorder. Temperatures up to $0.005 \mathrm{~K}$ have been obtained by this method.

A picture of an Adiabatic Demagnetization Cooler at NASA is shown in Fig. 27

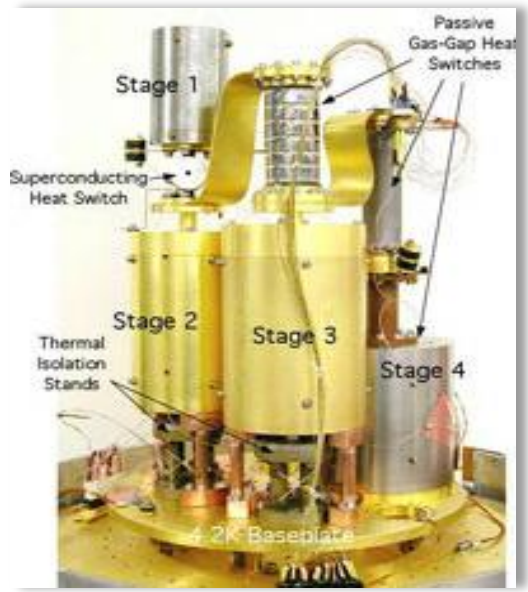

Fig.27 Picture of an Adiabatic Demagnetization Cooler in use at NASA 


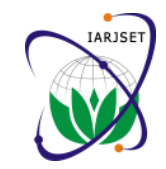

\section{IARJSET

5.6.2.Laser (Doppler) Cooling (Magneto Optical Trap): This is the most modern type of cooling with which we shall climb our last step. The principle of the method is illustrated in Fig.28. A set of crossed laser beams are directed to a sample of gas. The wavelength of the laser is so adjusted that more photons are absorbed by the atoms. An atom moving towards the photon will lose momentum on absorbing the photon and gets cooled whereas those atoms moving away from the photons gain momentum and hence energy. A sort of Doppler effect takes place here, that is, the atoms coming towards the photons

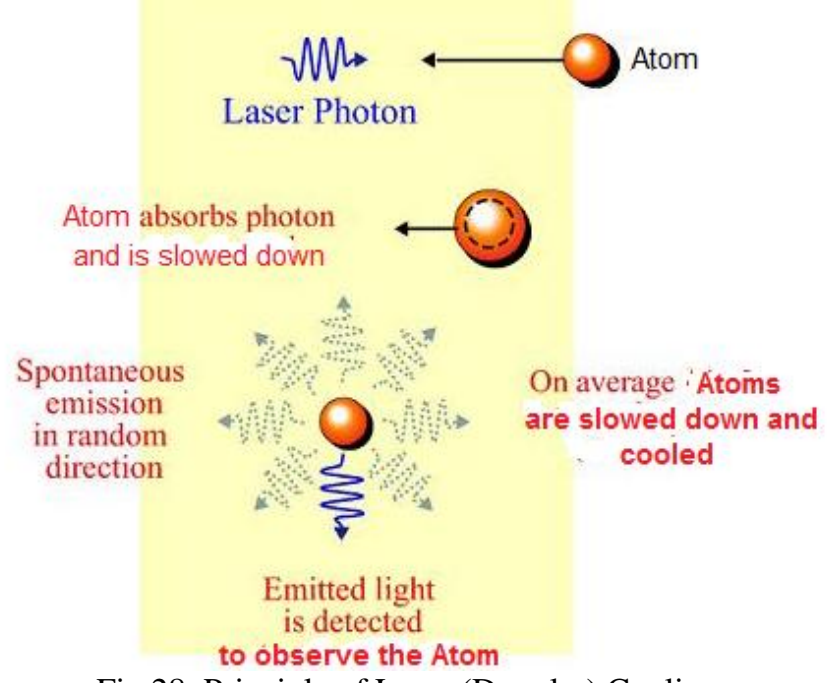

Fig.28 Principle of Laser (Doppler) Cooling

experience an altogether different frequency for the incoming photons (Doppler Effect) and hence the resultant cooling and the technique is called Doppler cooling. Within about $\mathbf{1 0}^{-\mathbf{8}}$ second of absorbing a photon, the atom emits another photon (spontaneous emission) and returns to its original state.. The emission of the second photon gives the atom a' kick' in the random direction. Considerable number of atoms are slowed down in this way and such slow moving atoms constitute a different material called optical molasses.

5.6.3 Sisyphus Cooling: Cooling still further in the process of Doppler cooling, creates a sort of 'Hill' and 'Valley'. A standing wave is created by the laser and each atom climbs the hill and is brought down to the valley by optical pumping. The atom is found to rise up and come down. The name Sisyphus is derived from Greek mythology where he was condemned by Gods and punished by asking him to push a boulder up a hill and bring it down

5.6.4.Magneto Optical Trap (MOT): As a part of the laser cooling, there is the Magneto Optical Trap (MOT) where some six crossed laser beams in the presence a magnetic field are directed to a cluster of atoms such that the cooled atoms get separated and the more energetic atoms escape from the sides of the potential well. This type of cooling is the evaporative cooling shown in Fig.29). Temperatures of the order of micro Kelvin $\left(\mathbf{1 0}^{-\mathbf{6}} \mathrm{K}\right)$ can be obtained by this method.

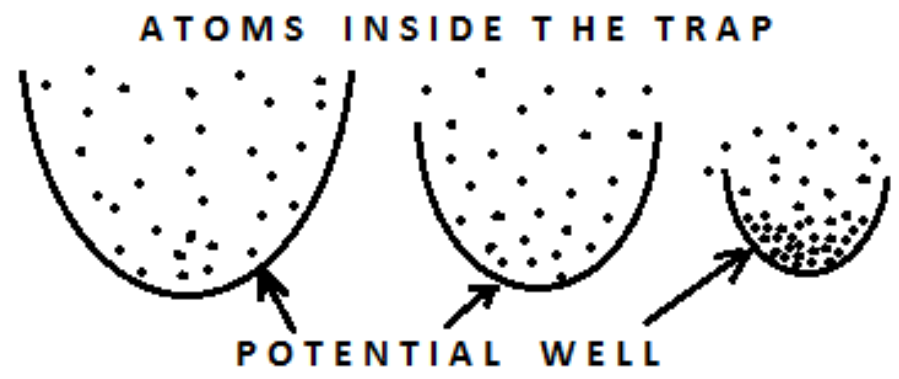

Fig.29 Illustration of Evaporative Cooling

5.7.The Bose Condensation: An Indian physicist, Satyendra Nath Bose (1894-1974) (Fig.31) working on Quantum Statistics of elementary particles wrote a paper in which he derived Planck's law of radiation without Classical Mechanics. He felt that the ideal scientist to appreciate his paper at his time was Albert Einstein (1879-1955) (Fig.30) So on June 4, 1924, Bose sent his paper directly to Einstein, writing:

"I have ventured to send you the accompanying article for your perusal and opinion. I am anxious to know what you think of it. You will see that I have tried to deduce the coefficient $8 \pi v^{2} / c^{3}$ in Planck's Law independent of the classical electrodynamics." 
Einstein instantly saw that Bose's work was very valuable, although even he did not see its full farreaching significance at first - this took him a few days.

Planck's quantum law actually contained a factor from classical physics: $8 \pi v^{2} / \mathrm{c}^{3}$. The mixing of classical and quantum theories in one equation had been a perpetual source of discomfort for physicists working in the field.

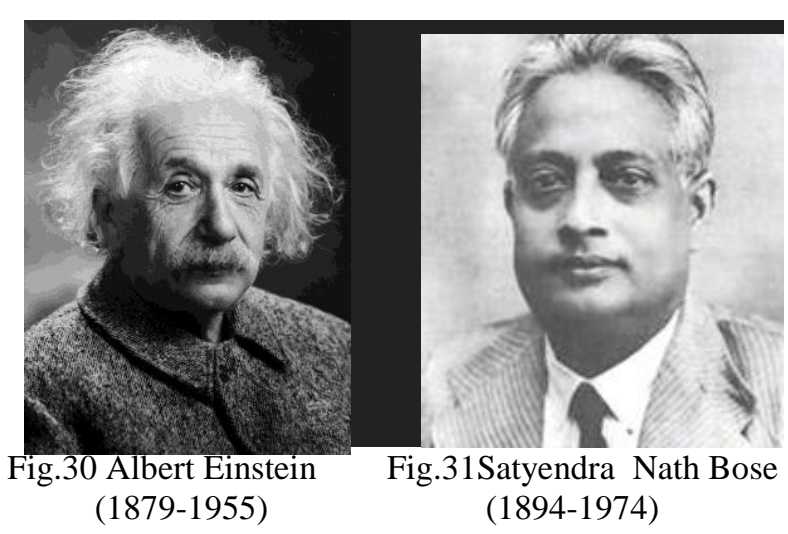

Bose had been able to produce the $8 \pi v^{2} / \mathrm{c}^{3}$ factor without using classical physics. Instead the factor arose naturally from the argument that photons with equal energy were indistinguishable from one another.

Einstein translated Bose's work into German and arranged for it to be published in the journal Zeitschrift für Physik. Einstein replied to Bose on July 24, saying that Bose's work was: an important step forward and I liked it very much.

\subsubsection{The Judgment of History:}

Bose's paper is now recognized as one of the most important theoretical papers in the founding of quantum theory. In fact, Bose had founded an entire new field: quantum statistics.

Einstein was impressed, and said that he liked it very much. Einstein translated the paper himself from English to German and submitted it for Bose to the Zeitschrift für Physik, which published it in 1924. (The Einstein manuscript, once believed to be lost, was found in a library at Leiden University in 2005.). Einstein then extended Bose's ideas to matter in two other papers. The result of their efforts is the concept of a Bose gas, governed by Bose-Einstein statistics, which describes the statistical distribution of identical particles with integer spin, now called bosons. Bosons, which include the photon as well as atoms such as helium-4 $\left({ }^{4} \mathrm{He}\right)$, are allowed to share a quantum state. Einstein proposed that cooling bosonic atoms to a very low temperature would cause them to fall (or "condense") into the lowest accessible quantum state, resulting in a new form of matter, the Fifth State, called Bose-Einstein Condensate.

We follow the literature given by Kompaneyets [2] and Richard Fitzpatrick [4]. The material to be cooled is Helium with an atomic number 2 and atomic mass 4 and hence denoted by ${ }_{2}^{4} \mathrm{He}$.. Helium has peculiar properties at low temperatures. Both the electrons in the cloud of helium atom and the protons and neutrons in the nucleus are in the 1s state. They all go in pairs and by the Pauli Exclusion principle, the spins are anti-parallel and hence the resultant spin is zero. Thus the photon of a helium atom qualifies to be a Boson which will permit us to apply Bose-Einstein Statistics.

Helium becomes a liquid at $4 \mathrm{~K}$ and it experiences a peculiar change of state at a temperature of $2.19 \mathrm{~K}$ and at atmospheric pressure. The behavior at gaseous state and at liquid state are two different things. But, however, liquid helium is a monatomic liquid and scientist S N Bose (1894-1974) (Fig.31) applied the Bose-Einstein Statistics to a helium gas with the values for liquid helium and obtained the transition temperature or the Bose temperature as follows:

Let $\mathrm{N}$ be the total number of particles in the system and occupying a gas volume, $\mathrm{V}$ and given by

$$
\mathrm{N}=\frac{2}{\sqrt{ } \pi} \cdot\left(\frac{2 \pi \mathrm{m} \mathrm{kT}}{h^{2}}\right)^{\frac{3}{2}} \mathrm{~V} \int_{0}^{\infty}\left(\frac{\sqrt{\mathrm{x}}}{\mathrm{e}^{\mathrm{x}}-1}\right) \mathrm{dx} . \ldots \ldots \ldots(19
$$

where $\mathrm{T}$ is the absolute thermodynamic temperature, $\mathrm{k}$ the Boltzmann constant the value of which is $1.38 \times 10^{-23} \frac{\mathrm{J}}{\mathrm{K}}$, $\mathrm{m}$ the mass of the particle which here is the mass of one helium atom and is equal to $6.65 \times 10^{-27} \mathrm{~kg}, \mathrm{~h}$ the Planck's constant equal to $6.63 \times 10^{-34} \mathrm{Js}$ and $\mathrm{N}$ can be the Avagadro's number equal to $6.02 \times 10^{23}$.

The integral on the right of equation (1) can be solved as

$$
\int_{0}^{\infty}\left(\frac{\sqrt{\mathrm{x}}}{\mathrm{e}^{\mathrm{x}}-1}\right) \mathrm{dx}=\frac{\sqrt{ } \pi}{2} \sum_{n=1}^{\infty} \frac{1}{n^{\frac{3}{2}}}=\frac{\sqrt{ } \pi}{2} \times 2.612=2.31
$$

Thus the equation ( ) may be re-written as

$$
\mathrm{N}=\frac{2}{\sqrt{ } \pi} \cdot\left(\frac{2 \pi \mathrm{m} \mathrm{kT}}{h^{2}}\right)^{\frac{3}{2}} \mathrm{~V}(2.31)
$$




\section{International Advanced Research Journal in Science, Engineering and Technology \\ ISO 3297:2007 Certified}

Vol. 5, Issue 3, March 2018

$$
\begin{aligned}
\therefore\left(\frac{2 \pi \mathrm{m} \mathrm{kT}}{\mathrm{h}^{2}}\right)^{\frac{3}{2}} & =\left(\frac{\mathrm{N}}{\mathrm{V}}\right)\left(\frac{1}{2.31}\right)\left(\frac{\sqrt{ } \pi}{2}\right)=\left(\frac{\mathrm{N}}{\mathrm{V}}\right)\left(\frac{\sqrt{ } \pi}{4.62}\right) \\
\therefore\left(\frac{2 \pi \mathrm{m} \mathrm{kT}}{\mathrm{h}^{2}}\right) & =\left[\left(\frac{\mathrm{N}}{\mathrm{V}}\right)\left(\frac{\sqrt{ } \pi}{4.62}\right)\right]^{\frac{2}{3}} \\
\text { or } \quad \mathrm{T} & =\left(\frac{\mathrm{h}^{2}}{2 \pi \mathrm{m} \mathrm{k}}\right)\left[\left(\frac{\mathrm{N}}{\mathrm{V}}\right)\left(\frac{\sqrt{ } \pi}{4.62}\right)\right]^{\frac{2}{3}}
\end{aligned}
$$

Now, consider 1 liter of helium so that $\mathrm{V}=1$ liter $=0.001=10^{-3}$ cubic meter and substituting other values, we get

$$
\begin{aligned}
\mathrm{T} & =\left[\frac{\left(6.63 \times 10^{-34}\right)^{2}}{(2 \times 3.142) \times\left(6.65 \times 10^{-27}\right) \times\left(1.38 \times 10^{-23}\right)}\right]\left[\left(\frac{1.773}{4.62}\right)\left(\frac{6.02 \times 10^{23}}{10^{-3}}\right)\right]^{\frac{2}{3}} \\
& =\frac{\left(44 \times 10^{-68}\right)}{\left(57.67 \times 10^{-50}\right)}\left[\left(\frac{1.773}{4.62}\right)\left(\frac{6.02 \times 10^{23}}{10^{-3}}\right)\right]^{\frac{2}{3}} \\
& =\left(0.763 \times 10^{-18}\right)\left[0.384 \times 6.02 \times 10^{26}\right]^{\frac{2}{3}} \\
& =\left(0.763 \times 10^{-18}\right)\left(2.312 \times 10^{26}\right)^{\frac{2}{3}} \\
& =\left(0.763 \times 10^{-18}\right)\left(2.157 \times 10^{18}\right) \\
& =(0.763 \times 2.157)=1.646 \\
\therefore & =1.646 \mathrm{~K}
\end{aligned}
$$

This matches with the temperature, $1.714 \mathbf{K}$ corresponding to vapor pressure of $1 \mathrm{~cm}$ of mercury (See Reading No. 8, Table-1)

\section{STEP - 4 (Contd.)}

\section{THE BOSE-EINSTEIN CONDENSATE}

6. The Discovery of the Bose-Einstein Condensate: We are now going to keep our final Step. With enough mathematical background, with a temperature as low as $0.844 \mathrm{~K}$ already reached by Onnes in 1911 and with modern methods of magnetic cooling and laser cooling already in existence, the year 1995 became a golden year of the $20^{\text {th }}$ century by actually arriving at the Bose-Einstein Condensate, the $5^{\text {th }}$ state of matter. In 1995 , the American physicists, Eric Allin Cornel (b.1961-) (Fig.32) and Carl Wieman (b.1951-) (Fig.33) of the university of Colarado, US cooled gas of Rubidium-87 atoms to about one-sixth of a millionth of a Kelvin. A German physicist, Wolfgang Ketterle (b.1957-) (Fig.34) working at Massachusetts Institute of Technology (MIT), US also arrived at the same result. All the three shared the 2001 Nobel Prize in Physics.

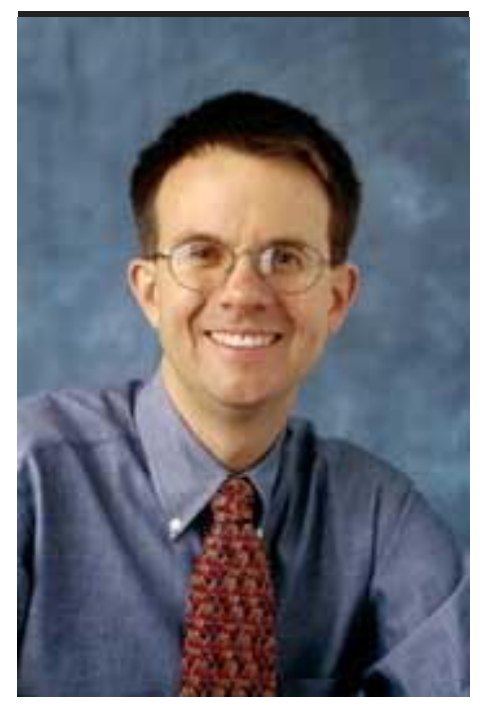

Fig.32 Eric Allin Cornel (b.1961-)

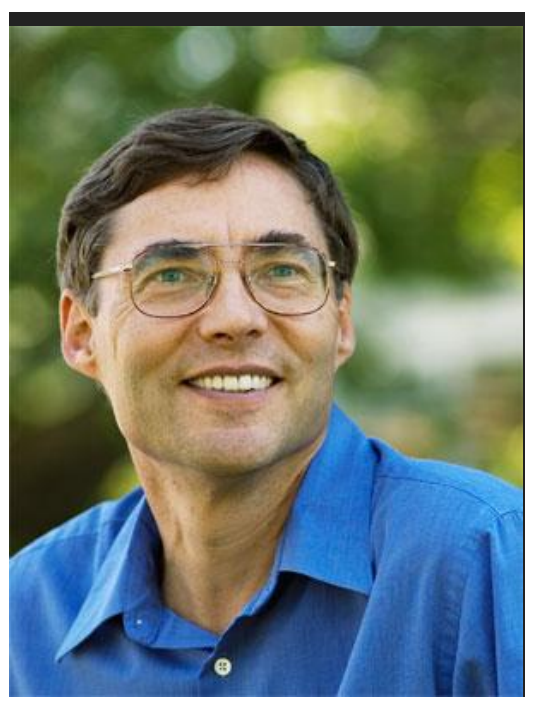

Fig.33 Carl Wieman (b.1951- )

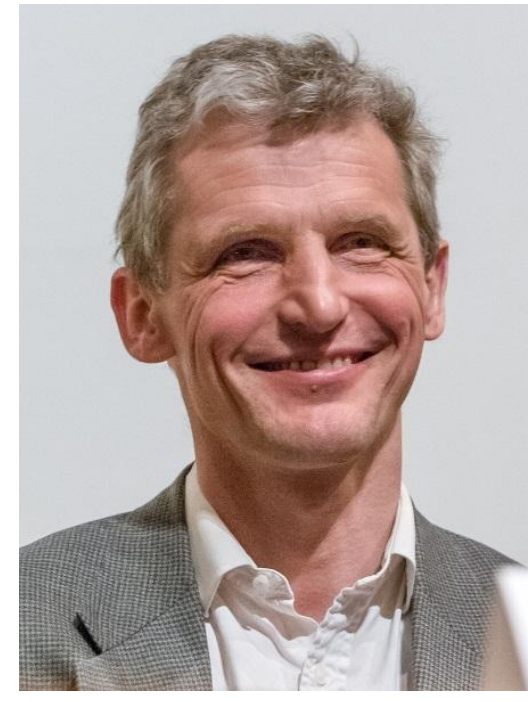

Fig.34 Wolfgang Ketterle (b. 1957)

I would like to give some excerpts from the Nobel Lecture by Wolfgang Ketterle [11] one of the winners of the Nobel Prize. The experimental arrangement is shown in Fig.35. Atoms are trapped by a strong magnetic field generated 
by two coils In the center the magnetic field vanishes which allows the atoms to spin flip and escape. Therefore the atoms are kept away from the center of the trap by a strong ( $35 \mathrm{~W})$ argon-ion laser beam ("Optical Plug") which exerts a repulsive force on the atoms. Evaporative

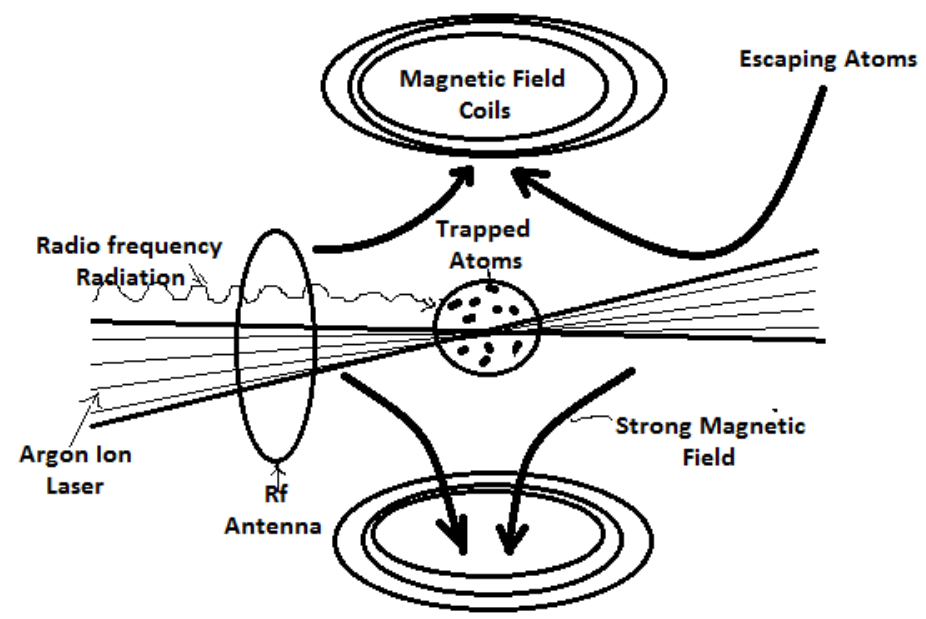

Fig.35. Pictorial illustration of the cooling process

cooling is controlled by radiofrequency radiation from an antenna. The radiofrequency selectively flips the spans of the most energetic atoms. The remaining atoms re-thermalize (at lower temperature) by collisions among themselves. Evaporative cooling is forced by lowering the radiofrequency.

The state of affairs taking place from the point of view of Quantum Mechanics is shown in Fig.36. At high temperature $\mathrm{T}$ trapped atoms behave as billiard balls with thermal velocity $\mathrm{v}$ and density $\mathrm{d}^{-3}$ as shown in Fig (a). As the temperature is lowered, the De Broglie wavelength $\lambda_{\mathrm{dB}}$ is proportional to $\mathrm{T}^{-\frac{1}{2}}$ wave packets. As shown in Fig (b). When the temperature $\mathrm{T}=\mathrm{T}_{\mathrm{c}}$ the critical temperature, $\mathrm{d}=\lambda_{\mathrm{dB}}$, the matter waves overlap as shown $\mathrm{i}(\mathrm{c}$ ). When $\mathrm{T}=0$, the giant matter wave appears with pure Bose condensate as shown in (d).

The scientists had a glimpse of the computer-generated photographs of the condensate at temperatures as low as 50 Nano Kelvin and the same is shown in Fig.37. The first diagram corresponds to the velocity distribution data when the condensate just begins to form, the second one is just after appearance and the third one the final condensate after sufficient evaporation. After the discovery, Cornel said: It is altogether a different kind of matter so cold that one can achieve only in a laboratory and not even in interstellar space where the temperature is slightly higher due the back ground radiation left out by the Big Bang.

The MIT researchers could attain temperatures as low as 0.45 Nano Kelvin in 2003. A view of the laboratory at MIT, US where the outstanding discovery was done, is shown in Fig. 38

A news item [9] which appeared in the Times of India, Bombay (now Mumbai), India dated 15 July 1995 reported from Washington DC, US and published by Agencies is shown in Fig.39.

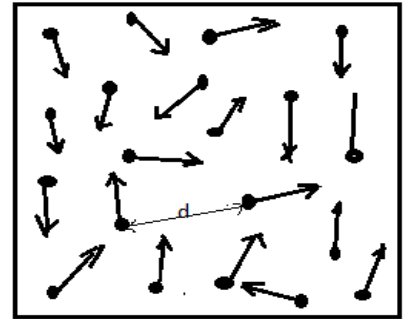

(a)

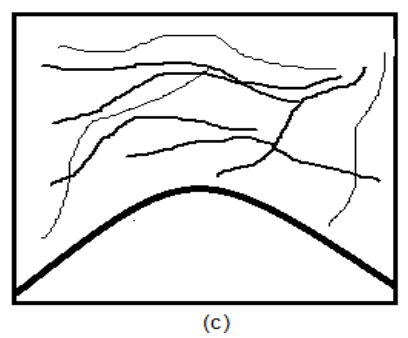

Fig.36. Illustration of the behavior of trapped atoms

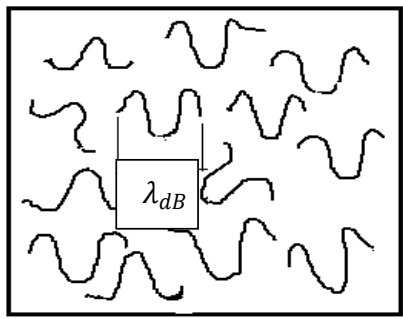

(b)

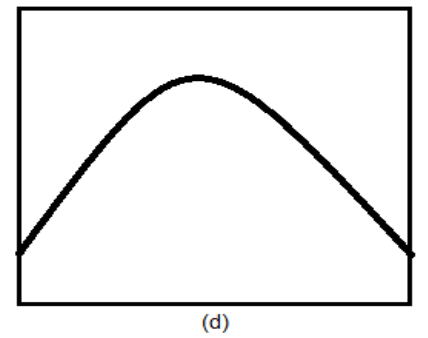




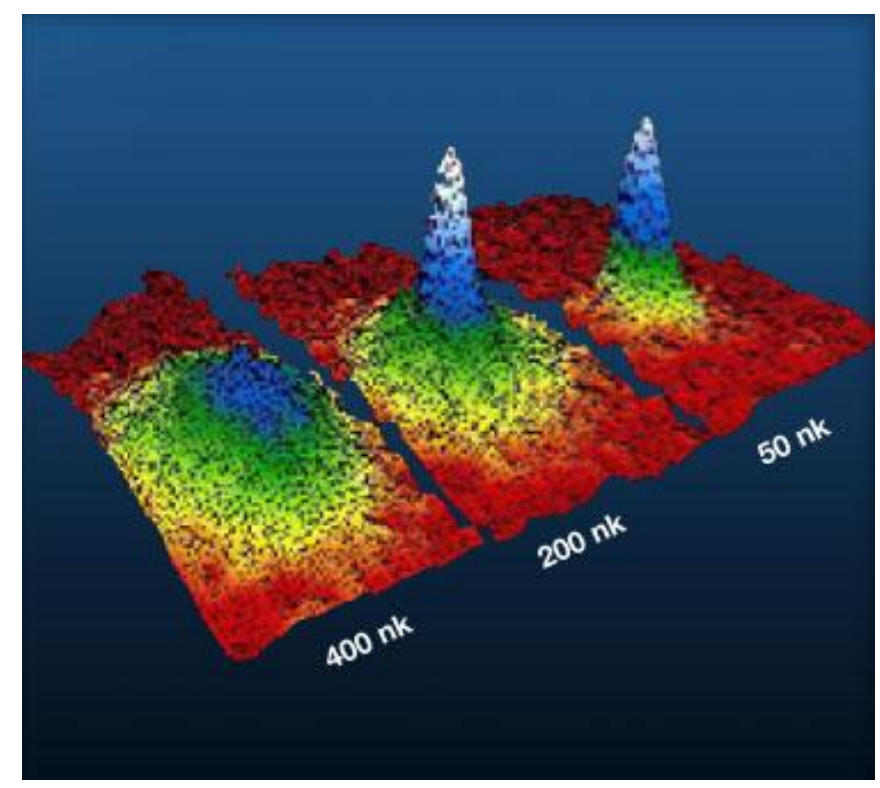

Fig 37 The gradual formation of the condensate at various extremely low temperatures

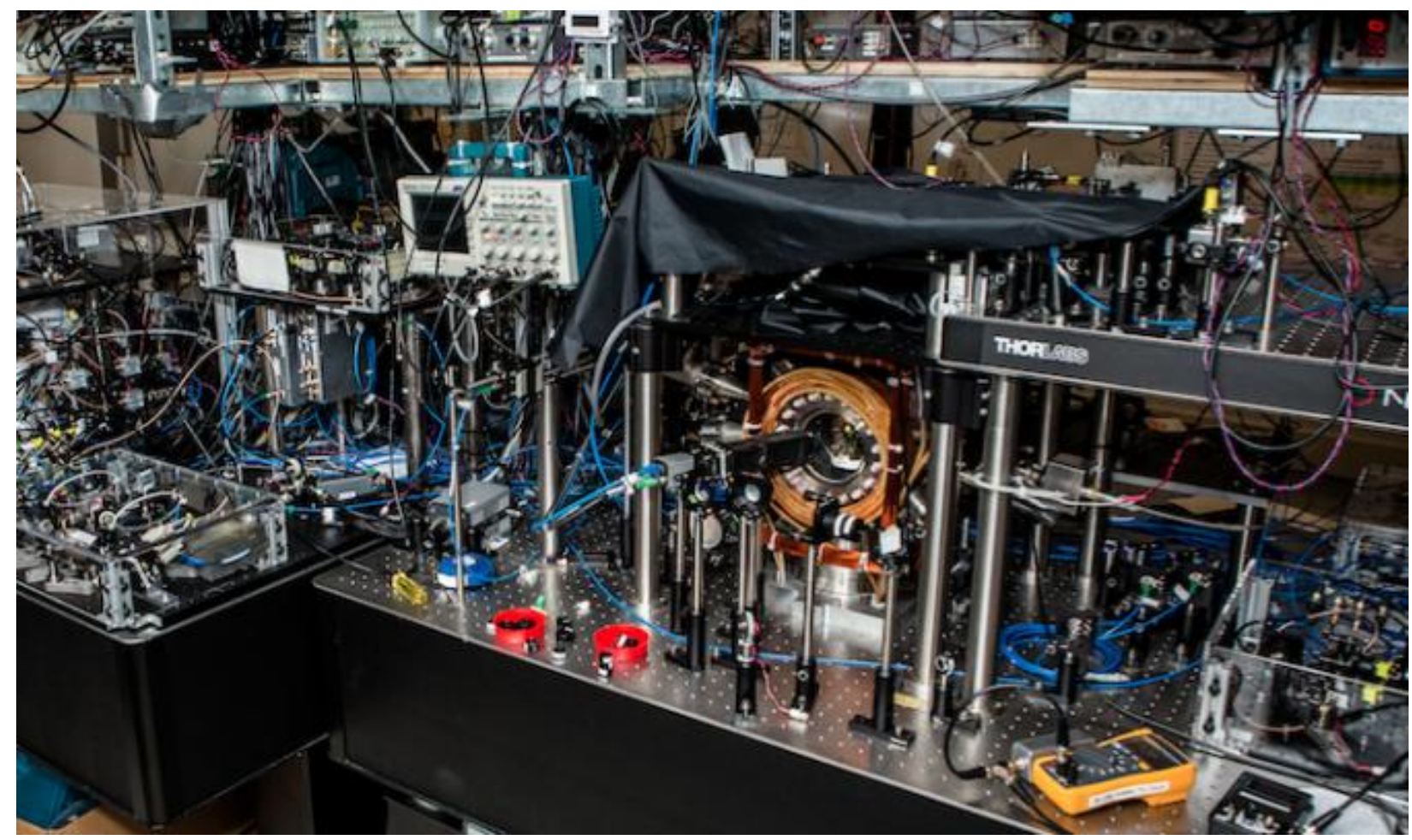

Fig.38. The Laboratory for cooling atoms at MIT, US 


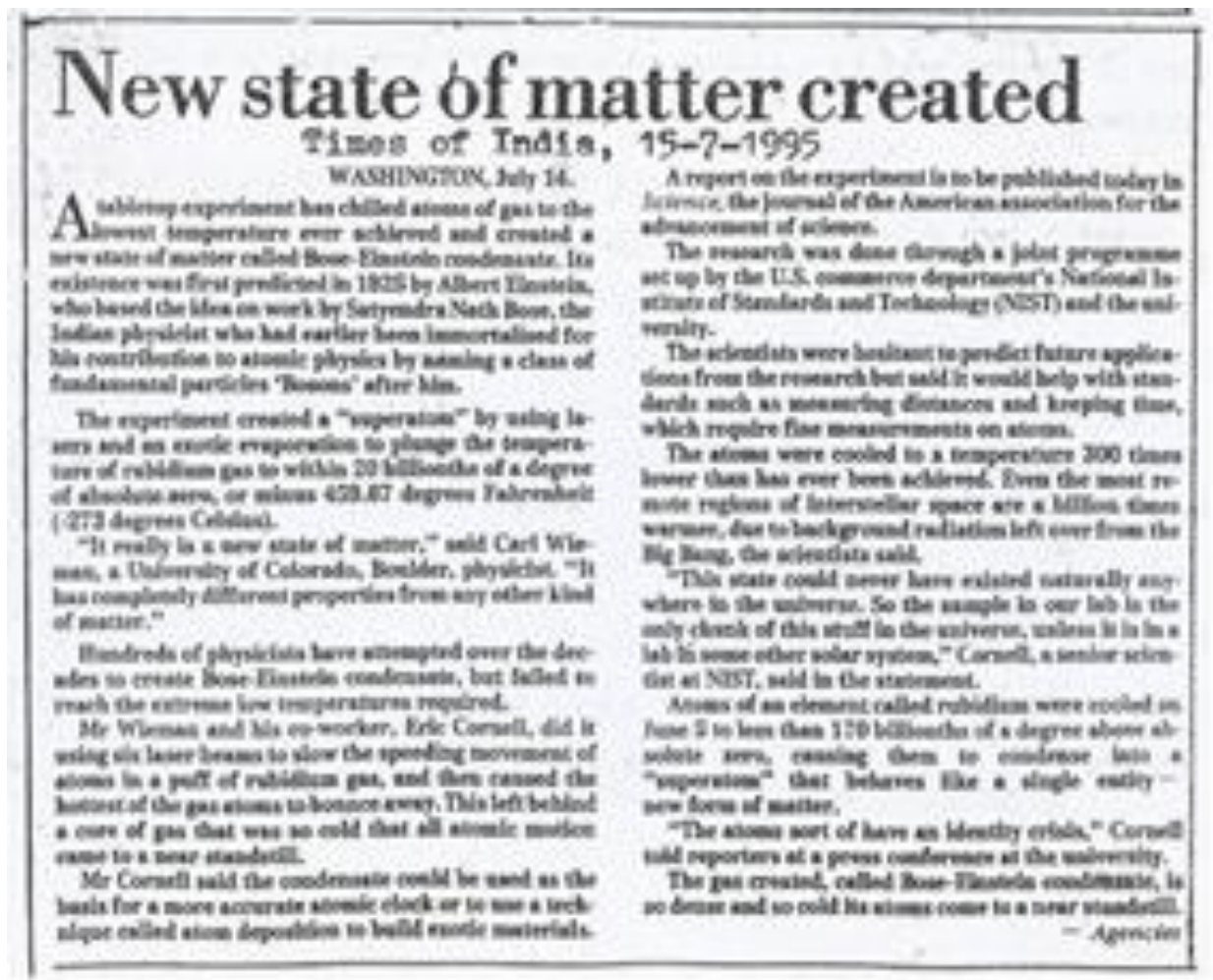

Fig.39 News item appeared in the daily of the Times of India, Mumbai, India. 15 July 1995

\section{CONCLUSION}

7.0. I hereby conclude my exhaustive paper. Before I do it, I would like to mention or rather I cannot ignore the valuable contribution of a renowned German chemist Walther Nernst (1864-1941) (Fig.40) in the topic of absolute zero. The topic is both in Physics and Chemistry rather it is more in Physics than in Chemistry as earlier investigators, as we have seen in the Introduction, were all physicists right from the $17^{\text {th }}$ century. The tussle between physicists and chemists is age-old and some of them are even at loggerheads. There is no wonder that the discovery of the Bose-Einstein Condensate has been done exclusively by 3 American physicists who were jointly awarded the 2001 Nobel Prize.

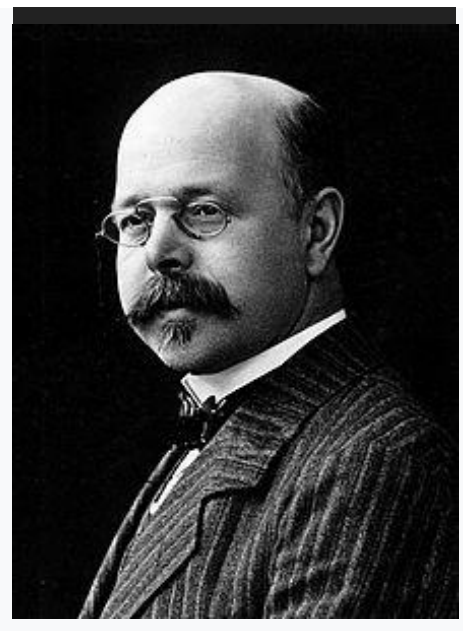

Fig.40.Walther Nernst (1864-1941)
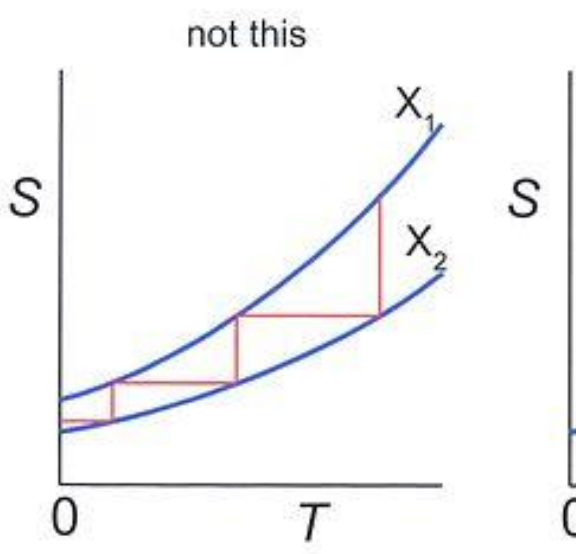

but this

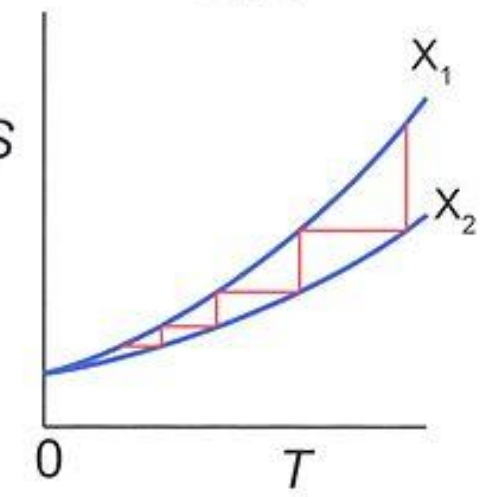

Fig.41 Illustration of the unattainability of Absolute Zero [10]

Research carried out by Nernst in the year 1912 brought out a theorem known as the Nernst Heat Theorem according to which "It is impossible by any procedure no matter how idealized to reduce the temperature of any system to the absolute zero of temperature in a finite number of finite operations". 


\section{International Advanced Research Journal in Science, Engineering and Technology}

ISO 3297:2007 Certified

Vol. 5, Issue 3, March 2018

Nernst formulated this statement as a Third Law of Thermodynamics, the Law of unattainability of Absolute Zero. The reason that $\mathrm{T}=0$ cannot be reached according to the third law is explained as follows: Suppose that the temperature of a substance can be reduced in an isentropic process by changing the parameter $\mathrm{X}$ from $\mathrm{X}_{2}$ to $\mathrm{X}_{1}$. One can think of a multistage nuclear demagnetization setup where a magnetic field is switched on and off in a controlled way. If there were an entropy difference at absolute zero, $T=0$ could be reached in a finite number of steps. However, at $T=0$ there is no entropy difference so an infinite number of steps would be needed. The process is illustrated in Fig.41. The graph on the left indicates the attainment of Absolute Zero in a finite number of steps if $S\left(0, X_{1}\right) \neq S\left(0, X_{2}\right)$. The graph on the right indicates the requirement of infinite number of steps since $S\left(0, X_{1}\right)=S\left(0, X_{2}\right)$.

From the point of view of thermodynamics, the infinitesimal change in Gibbs free energy $G$ is equal to the infinitesimal change in enthalpy $\mathrm{H}$ of the system as explained below:

The Gibbs free energy is given by $\mathrm{G}=\mathrm{H}-\mathrm{T} \mathrm{S}$ where $\mathrm{S}$ is the entropy and $\mathrm{T}$ the absolute temperature. Taking differentials we get

$$
\Delta \mathrm{G}=\Delta \mathrm{H}-\mathrm{T} \Delta \mathrm{S}
$$

In the limit when $\mathrm{T} \rightarrow 0$, that is

$$
\begin{gathered}
\lim _{\mathrm{T} \rightarrow 0} \Delta \mathrm{S}=0 \\
\text { whereby } \Delta \mathrm{G}=\Delta \mathrm{H}
\end{gathered}
$$

which is the theorem.

I am glad to mention that the 1920 Chemistry Nobel Prize was awarded to Walther Nernst

Mac Donald [3] in his book mentions of an interesting point by Sir Francis Simon (1893-1956) the pupil of Walther Nernst when some one asked him a question: "Do you think the road to Absolute Zero will ultimately become an uninteresting desert?" to which Sir Francis replied, more or less: Well, if it becomes a featureless desert, there won't be any way of crossing it, so the question answers itself."

As a sincere tribute to late Prof. Stephen Hawking, the visionary theoretical astrophysicist who earned global acclaim and who died on $14^{\text {th }}$ March 2018, the day of birth anniversary of late Albert Einstein, I am producing here his caricature (prepared by me) and related to this research paper. (Fig.42) I hope readers will appreciate the scientist's posture and his confidence over discoveries and findings.

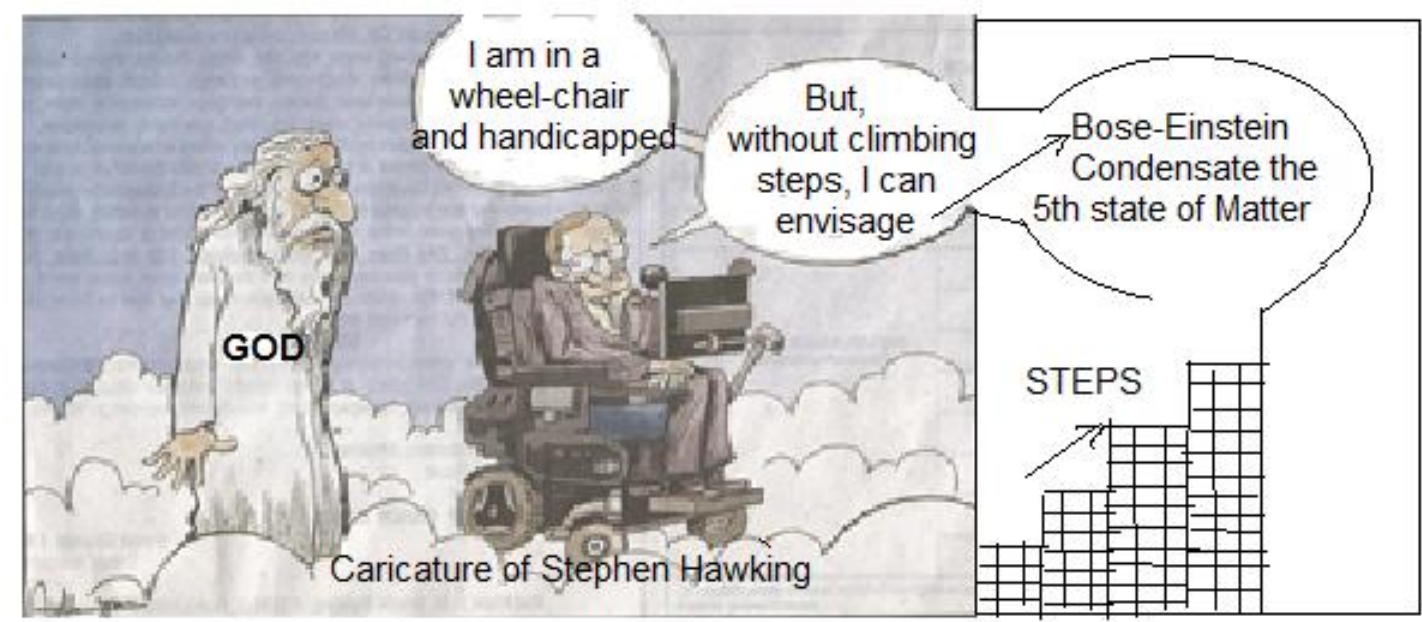

7.1.An interesting Corollary: Anne Mane Helmenstine Credit: [1] has mentioned of a "Negative Temperature”

Physicists have shown that it's possible to have a negative Kelvin (or Rankine) temperature. However, this doesn't mean particles are colder than absolute zero, but that energy has decreased. This is because temperature is a thermodynamic quantity that relates energy and entropy.

As a system approaches its maximum energy, its energy actually starts to decrease. This can lead to a negative temperature, even though energy is added. This only occurs under special circumstances, as in quasi-equilibrium states where spin is not in equilibrium with an electromagnetic field. 


\section{IARJSET \\ International Advanced Research Journal in Science, Engineering and Technology \\ ISO 3297:2007 Certified \\ Vol. 5, Issue 3, March 2018}

Strangely, a system at a negative temperature may be considered hotter than one at a positive temperature. The reason is because heat is defined according to the direction it would flow. Normally, in a positive-temperature world, heat flows from warmer (like a hot stove) to cooler (like a room). Heat would flow from a negative system to a positive system.

On January 3, 2013, scientists formed a quantum gas consisting of potassium atoms that had a negative temperature, in terms of motion degrees of freedom. Prior to this (2011), Wolfgang Ketterle and his team had demonstrated the possibility of negative absolute temperature in a magnetic system.

The new research into negative temperatures reveals mysterious behavior. For example, Achim Rosch, a theoretical physicist at the University of Cologne in Germany, has calculated that atoms at negative absolute temperature in a gravitational field might move "up" and not just "down".

Subzero gas may mimic dark energy, which forces the universe to expand faster and faster against the inward gravitational pull

7.2 Acknowledgement: Now-a-days due to the facility of internet, text books are ignored by students and teachers, forgetting that the information in a text book is nothing but a collection of research papers.Some of the very important material in this paper, especially the mathematical part, I have taken from a very famous classical book which I had followed in my graduate studies of the Bombay university in the sixties. The book of appreciation is, "Heat and Thermodynamics" by J.K. Roberts, Assistant Director of Research in Colloid Science in the University of Cambridge, the first edition of which is brought out in September 1928 and is my personal copy. J.K. Roberts is Sc.D.(Cantab) and a Fellow of Royal Society (FRS). I very sincerely thank Prof. Roberts and hereby acknowledge his presentation of various topics in that British style and the quality of printing by Blackie \& Son Limited (London and Glasgow) with several footnotes at many places and an Appendix and Index at the end.

\section{REFERENCES}

[1] Helmenstine Anne Mane-Google search, Absolute Zero, Last edited 4 April 2017

[2] Kompaneyets A.S. "Theoretical Physics", Foreign Language Publishing House, Moscow:1961. Bose Condensation, Part IV, Sec.43, p.475-6, Appendix. P.587

[3] Mac Donald D K C “Near Zero”-An Introduction to Low Temperature Physics, Vakil's Feffer and Simons Pvt. Ltd. Bombay, 1965. p.38, 49-52, 90-92.

[4] Richard Fitzpatrick of Univ. of Texas, Austin, US: 2016-01-25.

[5] Roberts J.K. "Heat and Thermodynamics":Blackie and Son Limited, London and Glasgow, 1943 Reprint. p.27-28, 100-120, 268-272.

[6] Roebuck J.R. "The Kelvin Temperature of the Ice Point”. Abstract, Phy. Rev.Vol.50, p.370, 15 Aug. 1936.

[7] Srinivasan M.R. "Physics for Engineers" New Age International (P) Ltd. 1995 ISBN: 81-224-0892-3, Ch.16-16.2, Joule Thomson Effect, p.423

[8] Taylor W. Llyod, "Physics the Pioneer Science, Vol.I, Dover Publications, 1959. P.254-257.

[9] The Times of India, Bombay dated 15 Jul 1995.

[10] Wikipedia:Last edited 1 Feb. 2018.

[11] Wolfgang Ketterle- "Nobel Lecture (8 Dec. 2001) - When atoms behave as waves"-Bose-Einstein Condensate and the atom laser. Pub. On 20 Nov. 2002. P.1131-1151.

General Reference:

[12] Tom Shachtman-“Absolute Zero and the Conquest of Cold” Mariner Books, Houghton Miffin Co., Text Book (A classical and popular book). Published 12 Dec. 2000.

\section{BIOGRAPHY}

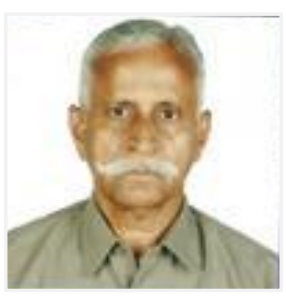

*Dr.(Prof.) V.C.A. Nair (b.15th Aug. 1939) is an Educational Physicist, Counselor, Research Guide and Consultant. He did his Masters in Physics from Mumbai University, India and Ph.D. from JJT University, Rajasthan also in India He is a Research Guide and distinguished alumni of JJT University. He is also a Chancellor designated Resource Person in the area of Physics in the University. He has to his credit over 4 decades of teaching Applied Physics in eminent Polytechnics in Mumbai and having taught nearly 16,000 students since 1965. He has published a number of research papers in Physics and Geophysics in International and UGC recognized Journals some of which can be seen in the net 'Google Search' when the name of the author is typed in that style. He is a Life Member of Indian Society for Technical Education which is an all India body. He had been to USA a number of times and visited eminent Universities such as Stanford, Harvard, MIT, University of California both at Berkeley and Los Angeles and University of San Francisco. At present Dr. Nair is a Research Guide for Physics at JJT University, Rajasthan-333001, India . He is member of the Editorial Board of this Journal. His Ph.D. Thesis is in Geophysics and he is working on topics such as Tides, Clouds, Global Warming and Climate Change. Editor.

*nairvca39@gmail.com. 